\title{
Establishment of the Low-Level Wind Anomalies over the Western North Pacific during ENSO Development*
}

\author{
Chia CHOU \\ Environmental Change Research Project, Institute of Earth Sciences, Academia Sinica, Taipei, Taiwan
}

(Manuscript received 10 June 2003, in final form 1 December 2003)

\begin{abstract}
The anomalous low-level anticyclone over the western North Pacific presents a link between El Niño and the western North Pacific-East Asian climate. During a La Niña event, however, the low-level wind anomalies over the western North Pacific reverse sign. The low-level wind anomalies move eastward from South Asia and are established over the western North Pacific in the fall of the El Niño (La Niña) developing year. The anomalous low-level anticyclone associated with El Niño is a response to suppressed convection. This suppressed convection is mainly induced by a cooling tendency associated with the vertical average of the anomalous horizontal advection of moist static energy that is defined as the mechanism of the horizontal advection of moist static energy. The El Niño-related sea surface temperature (SST) anomalies, over the eastern Pacific in particular, create negative meridional gradients of temperature and moisture over the western North Pacific. When the winter monsoon starts to dominate the Asian region, the northerly component of the winter monsoon transports low moist static energy air into South Asia that suppresses convection and induces the anomalous low-level anticyclone. Associated with the mean state of temperature and moisture, the meridional components of the anomalous low-level anticyclone transports cold and dry air to the southward branch and warm and moist air to the northward branch of the anomalous low-level anticyclone. This cooling-warming pattern of the anomalous horizontal advections of moist static energy tends to move the anomalous low-level anticyclone eastward. The mechanism of the horizontal advection of moist static energy implies a phase-locking behavior of the anomalous low-level anticyclone with the seasonal cycle of the mean state over the western North Pacific-East Asian region.
\end{abstract}

\section{Introduction}

Low-level wind anomalies over the western North Pacific play an important role in the relationship between the El Niño-Southern Oscillation (ENSO) and the western North Pacific-East Asian climate system (e.g., Chang et al. 2000a,b; Chen et al. 1992; Chou et al. 2003; Huang and Sun 1992; Kawamura et al. 2001; Lau and Bua 1998; Lau et al. 2000; Lau and Wu 2001; Lau and Nath 2000; Nitta 1987; Tanaka 1997; Wang et al. 2001; Weng et al. 1999; Wu and Wang 2000). An anomalous low-level anticyclone dominates the western North Pacific during the mature phase of El Niño, while an anomalous cyclone dominates the same region for a La Niña event. The anomalous low-level anticyclone (cyclone) often persists through the following spring and early summer, then induces a weak (strong) western North Pacific summer monsoon in the ENSO decaying year (Wang et al. 2000). The anomalous low-level an-

\footnotetext{
* Institute of Earth Sciences Contribution Number IESAS912.
}

Corresponding author address: Chia Chou, Environmental Change Research Project, Institute of Earth Sciences, Academia Sinica, Taipei, 115 Taiwan.

E-mail: chia@earth.sinica.edu.tw ticyclone associated with the western North Pacific subtropical ridge blocks the pre-mei-yu/baiu and mei-yu/ baiu front from moving southward, resulting in an enhanced East Asian summer monsoon (Chang et al. 2000a). The observation shows that the anomalous lowlevel anticyclone moves eastward from South Asia and is established over the western North Pacific in the fall of the El Niño developing year one season before El Niño matures (Wang and Zhang 2002). Before this anomalous low-level anticyclone is established, a different regime dominates the western North Pacific. For instance, a regime of an active intraseasonal oscillation becomes inactive (Wang and Zhang 2002) and a tendency of an anomalous low-level cyclone associated with a strong western North Pacific summer monsoon changes into the anomalous low-level anticyclone (Chou et al. 2003).

The anomalous low-level anticyclone over the western North Pacific associated with El Niño is believed to be a Rossby wave response to the suppressed convection over the western Pacific. The primary suspect for inducing the suppressed convection is the SST anomalies over the tropical western and eastern Pacific that are associated with El Niño. The remote warm SST anomalies over the eastern Pacific weaken the Walker 
circulation that might induce anomalous subsidence over the western Pacific (Lau and Nath 2000). In addition, the local cold SST anomalies over the western Pacific could also reduce convection ( $\mathrm{Su}$ and Neelin 2002; Wang et al. 2000). The SST anomalies over the Indian Ocean also play a role in enhancing the anomalous anticyclone over the western North Pacific in the mature phase of El Niño (Watanabe and Jin 2002). The SST anomalies in the Tropics appear in the spring and early summer of the El Niño developing year (year 0) and usually mature in the winter. The SST anomalies then start to decay in the following spring (year 1) and diminish in the following summer (Larkin and Harrison 2002; Rasmusson and Carpenter 1982). Comparing to the evolution of the anomalous low-level anticyclone discussed above, the associated SST anomalies appear one or two seasons earlier than the low-level anticyclone and diminish at least one season earlier than the anomalous low-level anticyclone. This inconsistency presents two interesting questions. The first is related to the establishment of the anomalous low-level anticyclone in the developing phase of El Niño. The pattern of the cold SST anomalies over the western Pacific and the warm SST anomalies over the eastern Pacific has already existed in the summer prior to the mature El Niño. If both warm and cold SST anomalies are responsible for suppressing convection over the western North Pacific, why is the corresponding anomalous low-level anticyclone established over the western North Pacific in the fall of the El Niño developing year, which is one season after the appearance of the SST anomalies? By analyzing the observations, Wang and Zhang (2002) suggest combined effects of the remote forcing of the warm SST anomalies over the eastern Pacific, tropical-extratropical interaction, and local atmosphere-ocean interaction for the establishment of the anomalous low-level anticyclone over the western North Pacific. The second question is related to the persistence of the anomalous low-level anticyclone in the decaying phase of El Niño. If the SST anomalies over the eastern and western $\mathrm{Pa}$ cific are the main forcing for the anomalous low-level anticyclone, why does the anomalous low-level anticyclone still exist when the SST anomalies diminish in the early summer of the El Niño decaying year? A feedback of an atmosphere-ocean interaction between the local SST anomalies and the anomalous low-level anticyclone is proposed by Wang et al. (2000) and Lau and Nath (2003).

In this study, I focus on the first question by using an atmospheric model with intermediate complexity (Neelin and Zeng 2000; Zeng et al. 2000, hereafter ZNC). A brief review of this model is in section 2, along with a description of the experiment design and the observed data used in the analysis. The observations are analyzed first to identify the establishment of the anomalous low-level anticyclone and these results are shown in section 3. Model simulations forced by prescribed ENSO SST are used to examine the effect of the ENSO
SST anomalies in section 4. In section 5, by the analysis of the moist static energy budget, mechanisms that induce the anomalous low-level anticyclone over the western North Pacific in an El Niño event are examined. Section 6 discusses the eastward movement of the anomalous low-level anticyclone, which is followed by discussion and conclusions in section 7 .

\section{The model and experiment design}

\section{a. The model}

To examine mechanisms establishing the anomalous low-level anticyclone over the western North Pacific, an atmospheric model of intermediate complexity (Neelin and Zeng 2000) and a simple land surface model (ZNC) with prescribed SST are used. Based on the analytical solutions derived from the Betts-Miller moist convective adjustment scheme (Betts and Miller 1993), typical vertical structures of temperature, moisture, and winds for deep convection are used as leading basis functions for a Galerkin expansion (Neelin and Yu 1994; Yu and Neelin 1994). The atmospheric model constrains the flow by quasi-equilibrium thermodynamic closures and is referred to as QTCM1 (quasi-equilibrium tropical circulation model with a single vertical structure of temperature and moisture for deep convection). In QTCM1, the vertical structure of horizontal winds is divided into the baroclinic and barotropic components (see Fig. 1 of $\mathrm{ZNC}$ ). The vertical profile of temperature is associated with the moist adiabatic process, while the moisture profile is estimated from a typical profile of moisture in the tropical deep convective region. The convection in QTCM1 is driven by a measure of the projected convective available potential energy (CAPE) and the positive CAPE indicates the conditional instability at subgrid scale. Because the basis functions are based on vertical structures in convective regions, these regions are expected to be well represented and similar to the general circulation model (GCM) with the Betts-Miller moist convective adjustment scheme. Far from deep convective regions, QTCM1 is a highly truncated Galerkin representation equivalent to a two-layer model.

A cloud-radiation scheme (Chou and Neelin 1996; ZNC) simplified from the full radiation schemes (Harshvardhan et al. 1987; Fu and Liou 1993) is included. In QTCM1, deep and cirrocumulus/cirrostratus cloud fraction is estimated by an empirical parameterization (Chou and Neelin 1999). An intermediate land surface model (ZNC) is used to simulate the interaction between the atmosphere and land surface. This model simulates processes such as evapotranspiration and surface hydrology in a single land surface layer for the calculation of energy and water budgets. Net surface heat flux is estimated from solar and longwave radiation, evaporation, and sensible heat. Soil moisture is balanced by precipitation, evaporation, surface runoff, and ground runoff. In this study a modified QTCM1 version 2.3 is used. 


\section{b. Experiment design}

The control run is a 10-yr average forced by the observed SST monthly climatology that is derived from the 50-yr (1951-2000) National Centers for Environmental Prediction-National Center for Atmospheric Research (NCEP-NCAR) reanalysis using the empirical orthogonal function (EOF) reconstructed SST analysis of Smith et al. (1996) with a resolution of $2^{\circ} \times 2^{\circ}$. To simulate ENSO-related low-level wind anomalies, both El Niño and La Niña SST are used as the forcing. The ENSO experiments are forced by 2-yr SST from the ENSO developing year (year 0) to the ENSO decaying year (year 1). The El Niño SST is obtained from the composite of the six strongest El Niño events (1957/58, 1965/66, 1972/ 73, 1982/83, 1991/92, 1997/98). Similarly, the La Niña SST is calculated from the composite of the six strongest La Niña events (1970/71, 1973/74, 1975/76, 1988/89, 1998/99, 1999/2000). The simulated low-level wind anomalies are 10-yr averages from the differences between the simulations forced by the El Niño SST and the simulations forced by the La Niña SST. In this manner the low-level wind anomalies associated with El Niño are examined. For a La Niña event, the low-level wind anomalies reverse sign. To examine sensitivity of the effect of the SST anomalies in different regions, experiments with the SST anomalies over the eastern Pacific, the western Pacific, and the Indian Ocean are conducted, respectively. The model simulations are compared to the composite differences of $850-\mathrm{hPa}$ winds, derived from the NCEP-NCAR reanalysis (Kalnay et al. 1996) with a resolution of $2.5^{\circ} \times 2.5^{\circ}$, between the six strongest El Niño and the six strongest La Niña. A 22-yr monthly precipitation data derived by the Climate Precipitation Center (CPC) Merged Analysis of Precipitation (CMAP; Xie and Arkin 1997) is also used, but the precipitation composite differences are calculated from three El Niño events $(1982 / 83,1991 / 92,1997 / 98)$ and three La Niña events $(1988 / 89,1998 / 99,1999 / 2000)$. A technique to suppress the dominant effect that induces the anomalous low-level anticyclone is also used. For instance, the climatology of the horizontal advection of moist static energy obtained from the control run is used for experiments with the monthly SST climatology and the El Niño SST, so the effect of the anomalous horizontal advection of moist static energy associated with El Niño is suppressed.

\section{Observation analysis}

Figure 1 shows the composite differences of SST, 850-hPa winds, and precipitation in the developing summer (year 0) prior to the mature phase of El Niño and the maturing winter (from the end of year 0 to the beginning of year 1) when El Niño is mature. The pattern of the SST anomalies over the tropical Pacific is roughly similar in both the developing summer and maturing winter except for the east coast of East Asia and the
South China Sea. The amplitude of the SST anomalies over the eastern and western Pacific is stronger in the maturing winter than in the developing summer. Modest warm SST anomalies over the Indian Ocean are also found in the maturing winter that do not exist in the developing summer. Instead, a weak east-west/coldwarm pattern of the SST anomalies is found. These cold-warm SST anomalies are associated with an atmosphere-ocean coupled mode (Lau and Nath 2000; Wang et al. 2003). The low-level wind anomalies over the western North Pacific are significantly different between these two seasons. In the developing summer, a weak anomalous cyclone is over the Philippine Sea and the South China Sea. This anomalous cyclone may be associated with the positive precipitation anomalies over the western North Pacific. An anomalous anticyclone is also found over the East China Sea, Korea, and Japan (Chou et al. 2003; Wang et al. 2001). The westerly wind anomalies associated with the El Niño warm SST anomalies over the eastern Pacific extend farther west into the equatorial western Pacific. In the maturing winter, a strong anomalous anticyclone is found over the western North Pacific and the El Niño-associated westerly wind anomalies extend only to $150^{\circ} \mathrm{E}$. The anomalous low-level anticyclone is believed to be a Rossby wave response to the suppressed convection associated with the low-level divergence anomaly over the western $\mathrm{Pa}$ cific. Figure $1 \mathrm{~b}$ shows strong negative precipitation anomalies over the western Pacific and the Maritime Continent that is associated with the suppressed convection. The suppressed convection might be induced by the warm SST anomalies over the eastern Pacific (Lau and Nath 2000), the local cold SST anomalies over the western Pacific (Wang et al. 2000), and the warm SST anomalies over the Indian Ocean (Watanabe and Jin 2002). The effects of the SST anomalies in different regions are examined in the next section.

Figure 1 implies that the anomalous low-level anticyclone over the western North Pacific is established between the developing summer and the maturing winter. The composite differences of the monthly SST, 850$\mathrm{hPa}$ wind, and precipitation anomalies from the September of the El Niño developing year to the January of the following year are shown in Fig. 2. In September (Fig. 2a), the weak anomalous cyclone and the westerly wind anomalies found in the developing summer (Fig. 1a) are still over the western North Pacific and the equatorial western Pacific, respectively. However, an anomalous low-level anticyclone is found over the west of the Indian subcontinent. This anomalous low-level anticyclone over South Asia may be linked to the suppressed convection over the western equatorial Pacific (Lau and Nath 2000). This anomalous anticyclone moves eastward to the vicinity of the South China Sea and the Philippine Sea and replaces the anomalous cyclone (Fig. 2) in October. The anomalous anticyclone is enhanced and positive SST anomalies appear along the east coast of East Asia in the mature phase of El 


\section{(a) JJA(0): El Nino - La Nina}

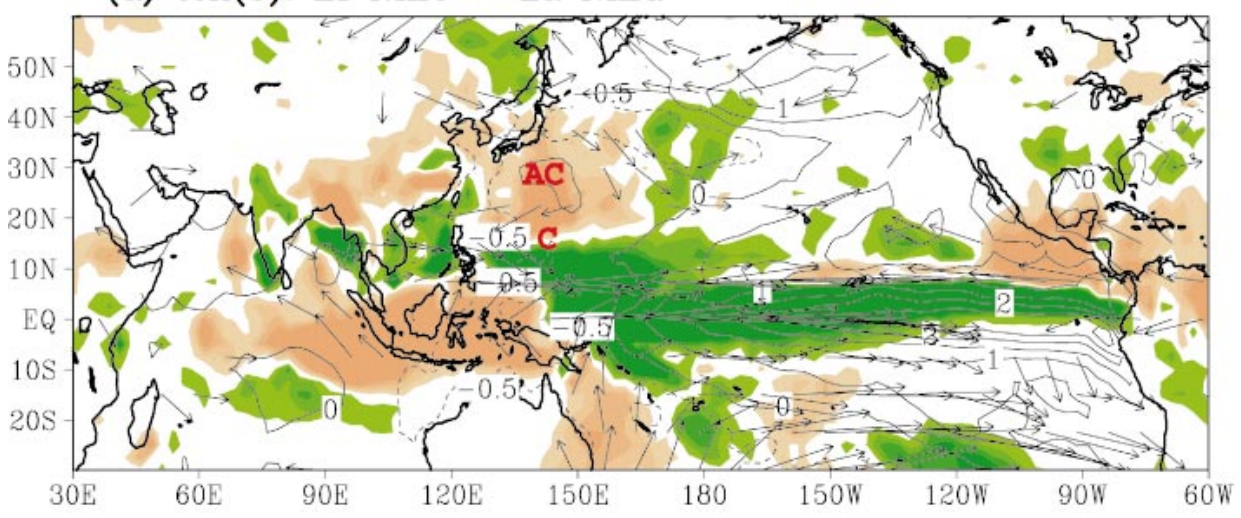

(b) $\mathrm{D}(0) \mathrm{JF}(1)$

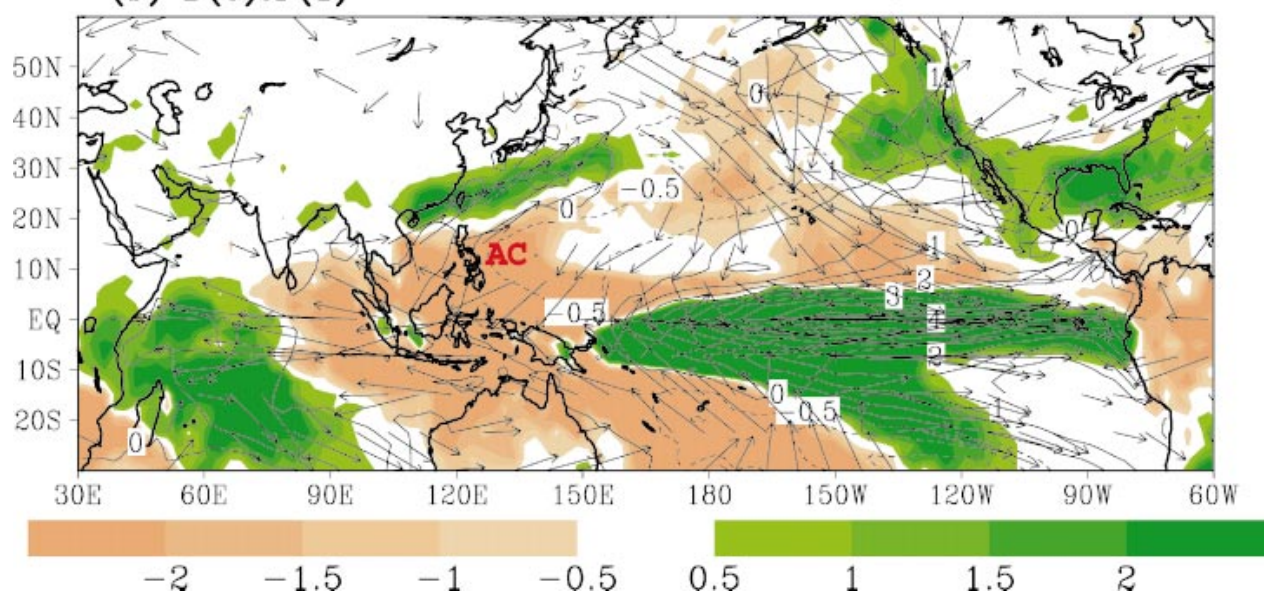

FIG. 1. Composite differences of the observed SST (contour), $850-\mathrm{hPa}$ winds, and precipitation (shading) between the El Niño and La Niña events for (a) $\mathrm{JJA}(0)$ and (b) $\mathrm{D}(0) \mathrm{JF}(1)$. Contour interval for $\mathrm{SST}$ is $0.5^{\circ} \mathrm{C}$.

Niño (Figs. 2d and 2e). Wang et al. (2000) suggest an atmosphere-ocean coupling between the anomalous low-level anticyclone and the SST anomalies over the western North Pacific. This coupling mechanism would sustain the anomalous low-level anticyclone for one to two more seasons over the western North Pacific (Lau and Nath 2003). Figure 2 also shows eastward retreat of the westerly wind anomalies associated with the El Niño warm SST anomalies over the eastern Pacific.

The eastward movement of the anomalous low-level anticyclone is associated with eastward movement of the low-level divergence anomaly and the suppressed convection. Figure 2 shows that the negative precipitation anomalies associated with the suppressed convection move slightly eastward from the Indian subcontinent to the western North Pacific. In addition, the eastward movement of the anomalous low-level anticyclone and the suppressed convection seems to be locked with the seasonal cycle. When the negative precipitation anomalies move eastward (Fig. 2), the warm and cold SST anomalies over the tropical Pacific remain stationary. If the SST anomalies over the tropical Pacific are responsible for the eastward movement of the anomalous anticyclone and the suppressed convection, how do the stationary SST anomalies over the Pacific induce the eastward movement of the anomalous low-level anticyclone? If this is not the case, what does induce the eastward movement of the anomalous anticyclone and the suppressed convection? The warm SST anomalies over the Indian Ocean do move eastward slightly during the developing phase of El Niño (Fig. 2) because of the atmosphere-ocean interaction (Lau and Nath 2000, Wang et al. 2003). However, are these modest warm SST anomalies over the Indian Ocean strong enough to induce the suppressed convection that moves eastward and is responsible for the eastward movement of the anomalous low-level anticyclone? Possible mechanisms are examined in section 6.

\section{Simulations of the low-level wind anomalies \\ a. Control experiments}

Figure 3 shows the differences of the $850-\mathrm{hPa}$ winds and precipitation between the experiments forced by the 
(a) $\operatorname{SEP}(0)$ : El Nino - La Nina

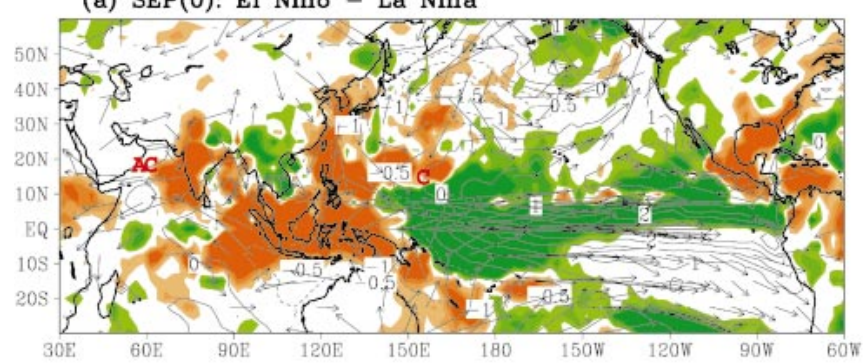

(b) $\operatorname{OcT}(0)$ 3

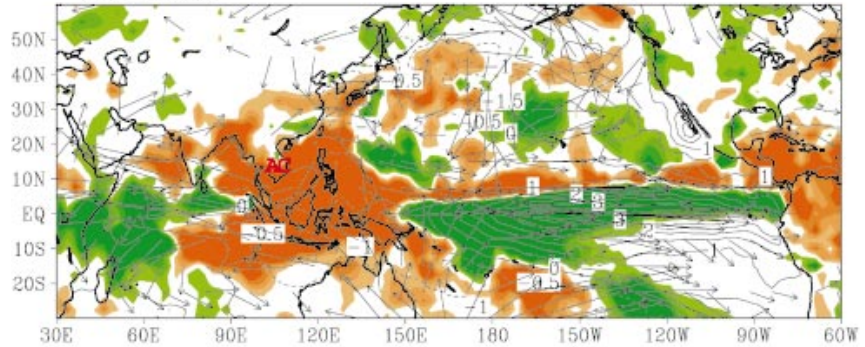

(c) $\operatorname{Nov}(0)$

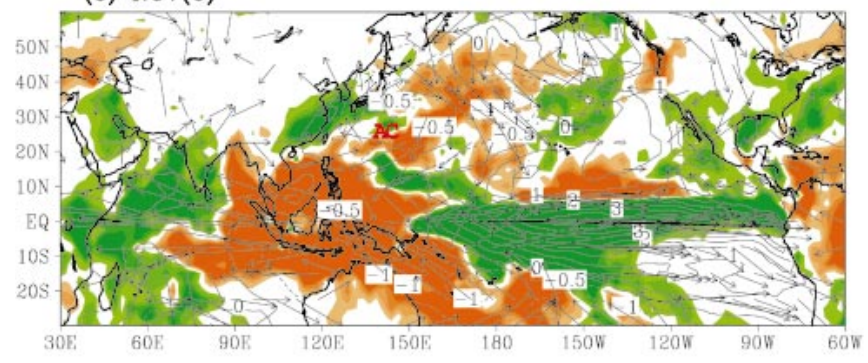

(d) $\operatorname{DEC}(0)$

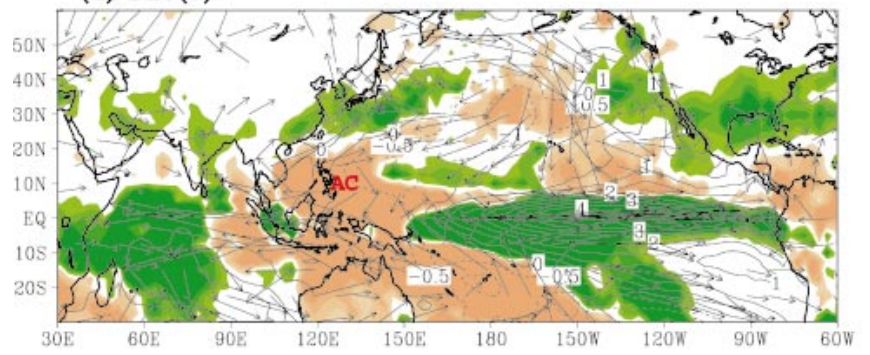

(e) JAN(1)

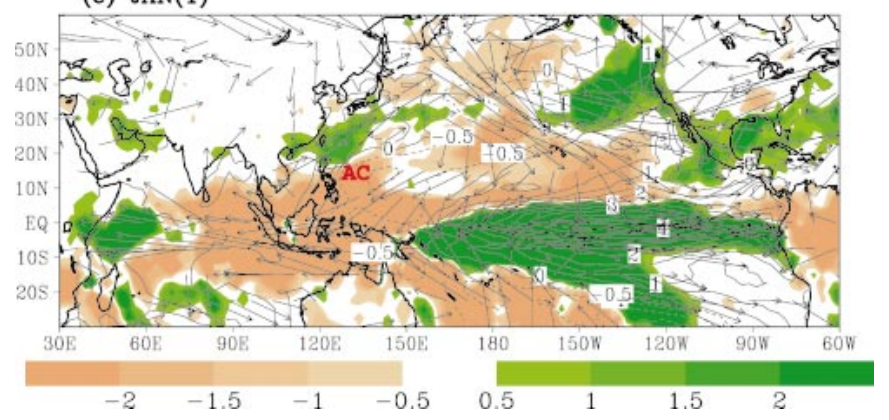

FIG. 2. As in Fig. 1 but for (a) $\operatorname{Sep}(0)$, (b) $\operatorname{Oct}(0)$, (c) $\operatorname{Nov}(0)$, (d) $\operatorname{Dec}(0)$, and (e) Jan(1). 
(a) JJA(0): all SSTA

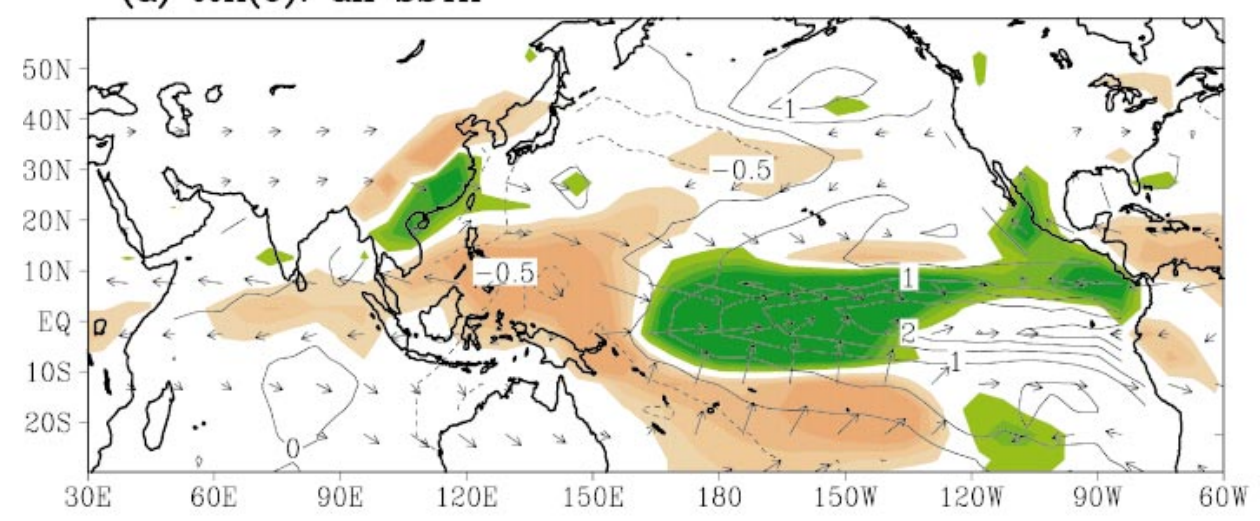

(b) $\mathrm{D}(0) \mathrm{JF}(1)$

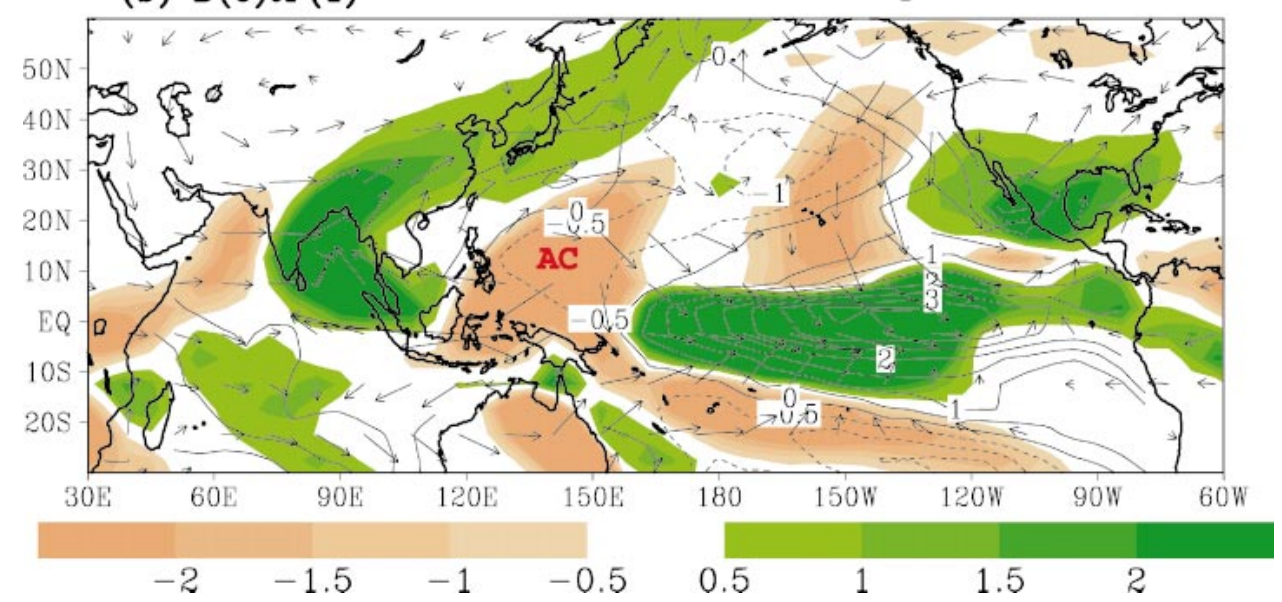

FIG. 3. As in Fig. 1 but for the differences of the model simulations between experiments with the El Niño and La Niña SST.

El Niño SST and La Niña SST. Note that the SST anomalies shown in Fig. 3 are the same as those in Fig. 1. For the maturing winter (Fig. 3b), the anomalous lowlevel anticyclone over the western North Pacific is well simulated. The westerly wind anomalies associated with the warm SST anomalies over the eastern Pacific extend westward to $150^{\circ} \mathrm{E}$, which is similar to Fig. 1b. The negative precipitation anomalies associated with the suppressed convection over the western Pacific are also simulated, but these negative precipitation anomalies do not extend as far westward into the eastern part of the Indian Ocean as the observation shown in Fig. 1b. In the developing summer (Fig. 3a), a similar but weaker anomalous anticyclone also dominates the western North Pacific. The westerly wind anomalies associated with the El Niño warm SST anomalies extend a little more westward to $140^{\circ} \mathrm{E}$. Negative precipitation anomalies are also found over the western Pacific where the SST anomalies are negative, which indicates that the underlying cold SST anomalies may be a dominant forcing. However, the low-level wind anomalies and the negative precipitation anomalies over the western North
Pacific simulated by the model (Fig. 3a) are inconsistent with the observations (Fig. 1a). This discrepancy suggests that the model cannot adequately simulate processes, such as surface heat flux exchange proposed by Lau et al. (2000) and Wang et al. (2001), so the associated effect that should enhance the convection over the western North Pacific (Fig. 1a) is not strong enough to overcome the effect of the underlying cold SST anomalies.

\section{b. Impacts of the SST anomalies}

To understand the role of the SST anomalies over different regions in inducing the anomalous low-level anticyclone over the western North Pacific, the effects of the SST anomalies over the eastern Pacific, the western Pacific, and the Indian Ocean are examined separately. Figures $4 \mathrm{a}$ and $4 \mathrm{~b}$ show the results of the experiment forced by the ENSO SST only over the tropical eastern Pacific and the seasonal climatology of SST over the rest of the area. The anomalous low-level anticyclone is still over the western North Pacific in the ma- 
(a) JJA(0): E.P. SSTA

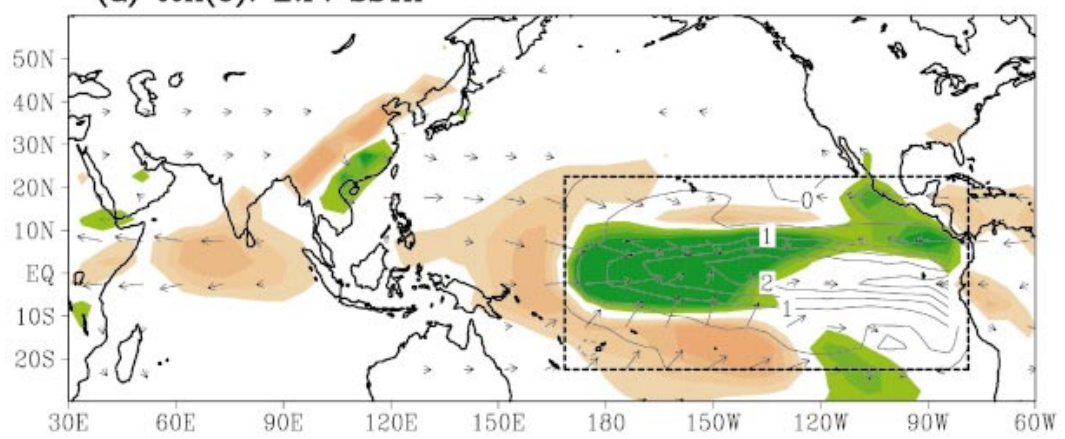

(b) D(0)JF(1): E.P. SSTA

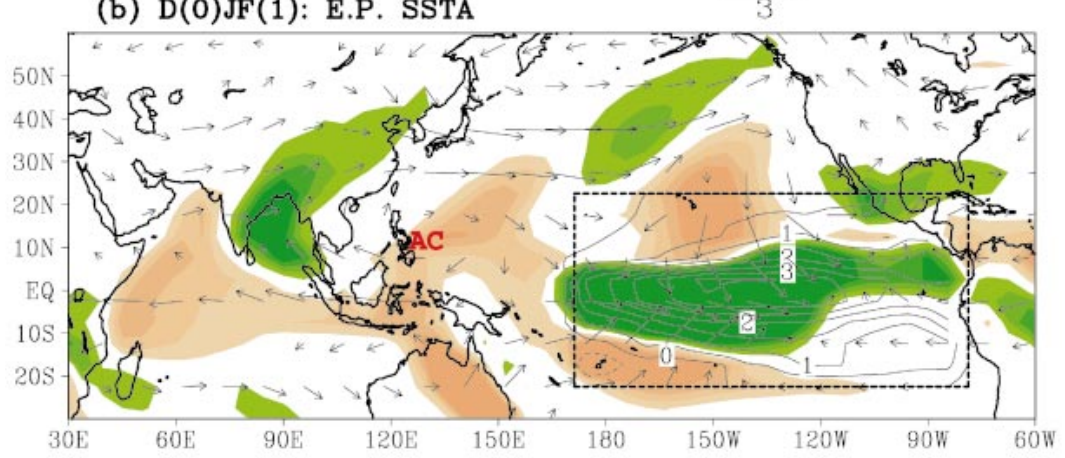

(c) D(0)JF(1): W.P. SSTA

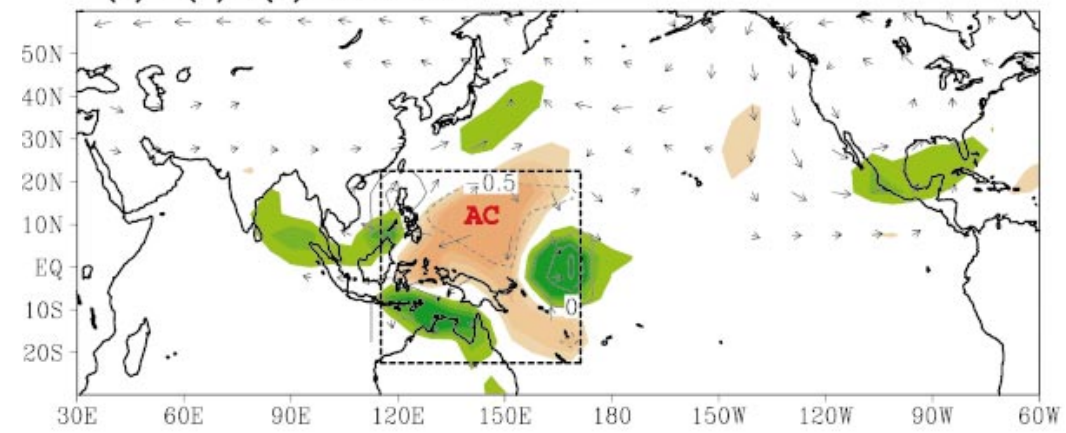

(d) $\mathrm{D}(0) \mathrm{JF}(1)$ : Indian SSTA

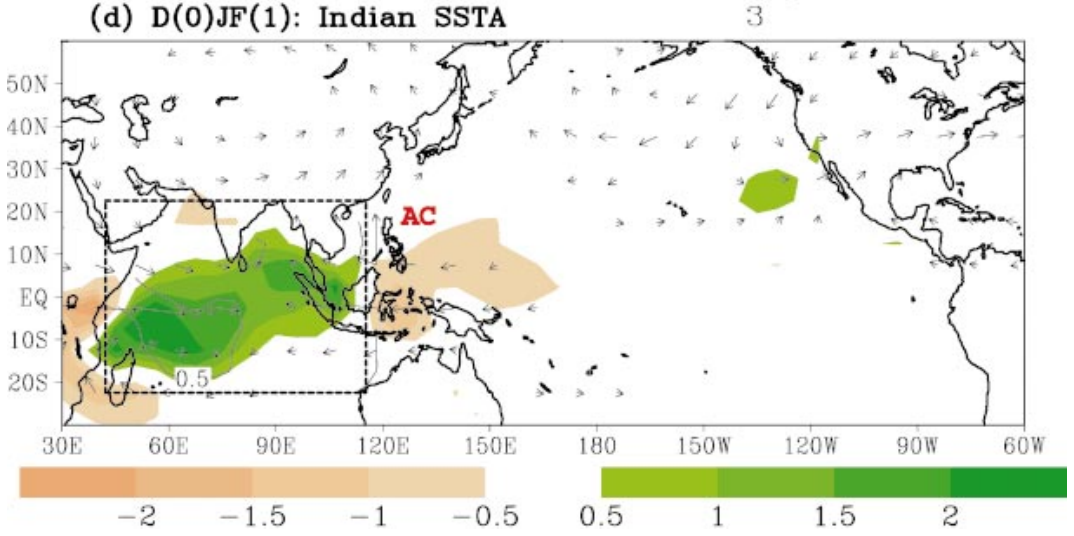

FIG. 4. As in Fig. 3 but the El Niño and La Niña SSTs are used within the box (dashed line); outside the box, the SST monthly climatology is used. The ENSO SST over the eastern Pacific in (a) the developing summer and (b) the maturing winter. The ENSO SST in the maturing winter over (c) the western Pacific and (d) Indian Ocean. 
turing winter but disappears in the developing summer. The westerly wind anomalies associated with the El Niño warm SST anomalies dominate the western Pacific in the developing summer but retreat to $150^{\circ} \mathrm{E}$ in the maturing winter. The simulated low-level wind anomalies over the western North Pacific (Figs. 4 and 4b) become similar to the observed wind anomalies (Fig. 1) in both the maturing winter and the developing summer. Without the effect of the cold SST anomalies over the western North Pacific in the developing summer, convection over the western North Pacific is slightly enhanced. An atmosphere-ocean interaction between the western North Pacific summer monsoon and the local ocean over the western North Pacific is suggested to be responsible for inducing this weak anomalous cyclone (Chou et al. 2003; Lau et al. 2000; Wang et al. 2001).

In the maturing winter without the cold SST anomalies over the western Pacific and the warm SST anomalies over the Indian Ocean, the anomalous low-level anticyclone and the associated negative precipitation anomalies over the western North Pacific (Fig. 4b) are weaker than in Figs. $1 \mathrm{~b}$ and $3 \mathrm{~b}$. It implies that the SST anomalies over the western Pacific and Indian Ocean should also have contributed to the enhancement of the anomalous low-level anticyclone over the western North Pacific. To further examine the effect of the SST anomalies over the western Pacific and Indian Ocean, experiments forced by the SST anomalies over the western Pacific and Indian Ocean are conducted and the results are shown in Figs. 4c and 4d, respectively. The cold SST anomalies over the western Pacific alone can induce an anomalous low-level anticyclone and the corresponding negative precipitation anomalies over the western North Pacific. The local cold SST anomalies suppress convection over the western Pacific by reducing evaporation and surface heat fluxes and induce a Rossby wave response that is responsible for producing an anomalous low-level anticyclone over the western North Pacific. The amplitudes of the wind and precipitation anomalies are compatible to the results of Fig. 4b, but weaker than the results of Fig. 3b. When the atmosphere is forced by the warm SST anomalies over the Indian Ocean, the corresponding anomalous low-level anticyclone and negative precipitation anomalies are also found over the western North Pacific, but with a much weaker amplitude (Fig. 4d). Thus, the SST anomalies over the eastern and western Pacific are the dominant factors for inducing the anomalous low-level anticyclone over the western North Pacific in the maturing winter, while the SST anomalies over the Indian Ocean have only a small contribution to the enhancement of the anomalous low-level anticyclone.

\section{Mechanisms for establishing the low-level wind anomalies}

The anomalous low-level anticyclone over the western North Pacific is a Rossby wave response to the suppressed convection over the western Pacific. Thus, the moist static energy budget is examined to understand the mechanisms that induce the suppressed convection. The most dominant mechanism is the anomalous horizontal advection of moist static energy vertically averaged through the troposphere. Two secondary effects, the net energy into the air column $\left(F^{\text {net }}\right)$ and the anomalous gross moist stability $\left(M^{\prime}\right)$, are also discussed.

\section{a. Moist static energy budget}

In QTCM1, the ENSO-induced change of the moist static energy budget vertically averaged through the troposphere can be written

$$
\begin{aligned}
\frac{p_{T}}{g} \bar{M} \boldsymbol{\nabla} \cdot \mathbf{v}_{\mathbf{1}}^{\prime}= & -\frac{p_{T}}{g}\langle\mathbf{v} \cdot \boldsymbol{\nabla}(q+T)\rangle^{\prime}+F^{\mathrm{net}^{\prime}} \\
& -\frac{p_{T}}{g} M^{\prime} \boldsymbol{\nabla} \cdot \overline{\mathbf{v}}_{\mathbf{1}},
\end{aligned}
$$

where $\left(\overline{)}\right.$ denotes the climatology, ()$^{\prime}$ is the anomalies induced by ENSO, ( ) denotes the first baroclinic mode under convective quasi-equilibrium constraints, and \langle\rangle denotes vertical average over the troposphere with $p_{T}$ as the depth of the troposphere; $T$ is atmospheric temperature, $q$ is moisture, $g$ is gravity, and $\mathbf{v}$ is horizontal velocity. The heat capacity at constant pressure, $C_{p}$, and the latent heat per unit mass, $L$, are absorbed by $T$ and $q$, so $T$ and $q$ are both in energy units; $M$ is the gross moist stability (Neelin and Yu 1994; Yu et al. 1998) and is defined by

$$
M=\left\langle\Omega\left(-\partial_{p} h\right)\right\rangle,
$$

where $h$ is moist static energy and $\Omega(p)$ is the vertical structure of vertical velocity from the baroclinic wind,

$$
\omega(x, y, p, t)=-\Omega(p) \boldsymbol{\nabla} \cdot \mathbf{v}_{\mathbf{1}}(x, y, t),
$$

where $\omega$ is pressure velocity. Here $\boldsymbol{\nabla} \cdot \mathbf{v}_{\mathbf{1}}$ is positive for low-level convergence and upper-level divergence; $\Omega(p)$ is positive, so $M$ is positive too. In (1) $F^{\text {net }}$ is defined as the net energy input into the atmospheric column:

$$
\begin{aligned}
F^{\text {net }}= & S_{t}^{\downarrow}-S_{t}^{\uparrow}-S_{s}^{\downarrow}+S_{s}^{\uparrow}-R_{t}^{\uparrow}-R_{s}^{\downarrow}+R_{s}^{\uparrow} \\
& +E+H,
\end{aligned}
$$

where subscripts $s$ and $t$ on the solar $\left(S^{\downarrow}\right.$ and $\left.S^{\uparrow}\right)$ and longwave $\left(R^{\uparrow}\right.$ and $R^{\downarrow}$ ) radiative terms denote surface and model top, and $R_{t}^{\downarrow} \approx 0$ has been used; $H$ is sensible heat flux and $E$ is evaporation.

The term on the left of (1) is an anomalous heating associated with the divergence anomaly, $\boldsymbol{\nabla} \cdot \mathbf{v}_{\mathbf{1}}^{\prime}$. In the Tropics, anomalous heating is associated with ascending motion, that is, $\boldsymbol{\nabla} \cdot \mathbf{v}_{\mathbf{1}}^{\prime}>0$, while anomalous cooling is associated with descending motion, that is, $\boldsymbol{\nabla} \cdot \mathbf{v}_{\mathbf{1}}^{\prime}<0$. The anomalous heating is balanced by the vertical average of the horizontal advection of moist static energy, net energy input into the atmospheric column, and an 
(a) $\mathrm{D}(0) \mathrm{JF}(1): 500 \mathrm{hPa}$ Omega
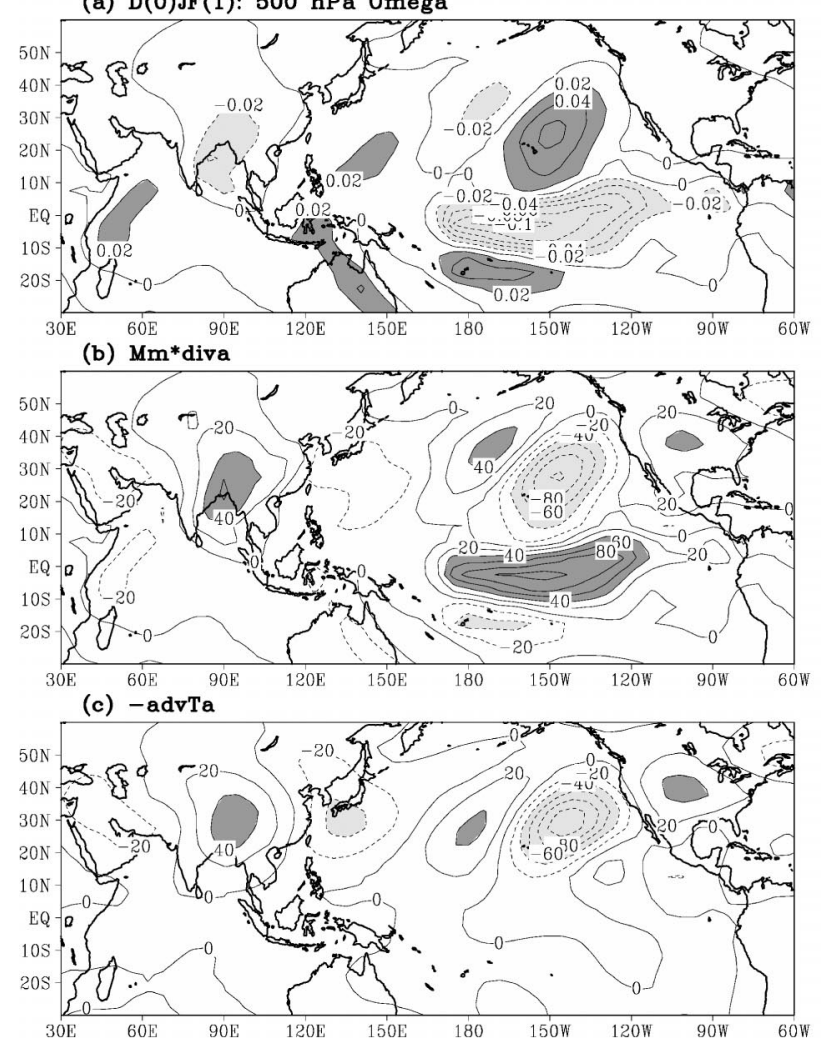

(d) - advqa

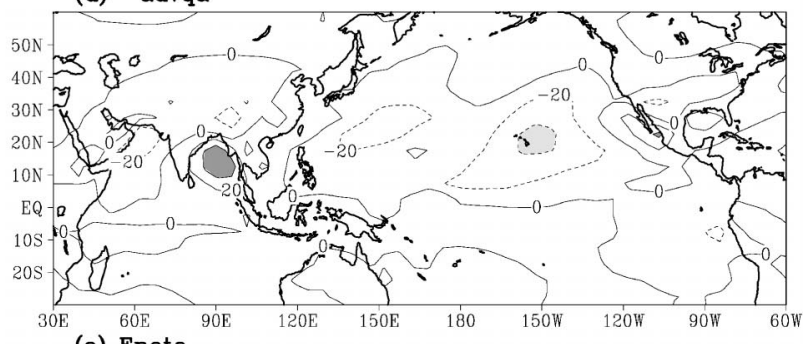

(e) Fneta
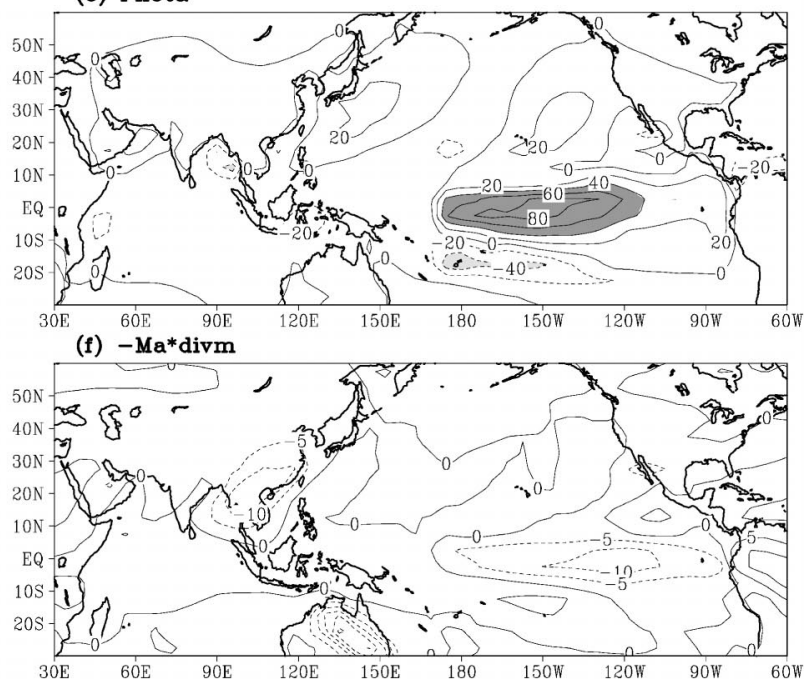

FIG. 5. Vertical pressure velocity and energy budget in the maturing winter for the experiment with the ENSO SST over the eastern Pacific (Figs. 4a,b): (a) $500-\mathrm{hPa} \omega^{\prime}$, (b) $p_{T} / g \bar{M} \boldsymbol{\nabla} \cdot \mathbf{v}_{\mathbf{1}}^{\prime}$, (c) $-p_{T} / g\langle\mathbf{v} \cdot \boldsymbol{\nabla} T\rangle^{\prime}$, (d) $-p_{T} / g\langle\mathbf{v} \cdot \boldsymbol{\nabla} q\rangle^{\prime}$, (e) $F^{\text {net }}$, and (f) $-p_{T} / g M^{\prime} \boldsymbol{\nabla} \cdot \overline{\mathbf{v}}_{1}$. Contour interval for $\omega^{\prime}$ is $0.02 \mathrm{~Pa} \mathrm{~s}^{-1}$. Contour interval for the energy budget is $20 \mathrm{~W} \mathrm{~m} \mathrm{~m}^{-2}$ except (e), which is $5 \mathrm{~W} \mathrm{~m}^{-2}$. Areas with dark shading are above 40 and areas with light shading are below $-40 \mathrm{~W} \mathrm{~m}^{-2}$.

anomalous gross moist stability $\left(M^{\prime}\right)$ mechanism. Since the simulated low-level wind anomalies over the western North Pacific, shown in Figs. 4a and 4b, are similar to the observation (Fig. 1), the moist static energy budget of the experiment in Figs. $4 \mathrm{a}$ and $4 \mathrm{~b}$ is examined. The focus is on the maturing winter when the anomalous lowlevel anticyclone is well established. Figure 5a shows that anomalous descending motion $\left(\omega^{\prime}>0\right)$ is found over the western North Pacific. This anomalous descending motion is associated with suppressed convection that induces the anomalous low-level anticyclone over the western North Pacific in Fig. 4b. Based on (1), the positive $\omega^{\prime}$ is associated with the negative $\bar{M} \boldsymbol{\nabla} \cdot \mathbf{v}_{\mathbf{1}}^{\prime}$ over the western North Pacific (Fig. 5b) that is balanced by the three terms on the right of (1), which are discussed next.

\section{b. Horizontal advection of moist static energy}

The first term on the right of (1) is an anomalous horizontal advection of moist static energy averaged over the troposphere. Figures $5 \mathrm{c}$ and $5 \mathrm{~d}$ show the components of temperature, $-\langle\mathbf{v} \cdot \nabla T\rangle^{\prime}$, and moisture, $-\langle\mathbf{v} \cdot \nabla q\rangle^{\prime}$, respectively. Note that the column-averaged advection differs from advection at a single level. A strong cooling and drying tendency is found over the western North
Pacific. This cooling and drying tendency is well aligned with the negative $\bar{M} \boldsymbol{\nabla} \cdot \mathbf{v}_{\mathbf{1}}^{\prime}$ over the western North Pacific (Fig. 5b). To examine the effect of $-\langle\mathbf{v} \cdot \nabla(T+q)\rangle^{\prime}$, a climatology of $-\langle\mathbf{v} \cdot \nabla(T+q)\rangle$ obtained from the control run with the SST monthly climatology is used for both El Niño and La Niña experiments, so the effect of $-\langle\mathbf{v} \cdot \boldsymbol{\nabla}(T+q)\rangle^{\prime}$ is suppressed. Figure 6a shows the results with the SST anomalies only over the eastern Pacific. Comparing to the results of Fig. 4b, the anomalous low-level anticyclone and the negative precipitation anomalies over the western North Pacific have disappeared. This indicates that $-\langle\mathbf{v} \cdot \boldsymbol{\nabla}(T+q)\rangle^{\prime}$ is a dominant effect on suppressing convection over the western North Pacific in the experiment with the SST anomalies over the eastern Pacific. A similar experiment with the SST anomalies over all oceans is shown in Fig. 6b. Without the effect of $-\langle\mathbf{v} \cdot \nabla(T+q)\rangle^{\prime}$, the anomalous low-level anticyclone over the western North Pacific (Fig. 6b) is much weaker than the result of Fig. 3b, even weaker than the result of Fig. 4c that is forced by the SST anomalies over the western Pacific. This implies that the effect of the horizontal advection of moist static energy also modifies the effects of the SST anomalies over the western Pacific and Indian Ocean on inducing the anomalous lowlevel anticyclone over the western North Pacific. 
(a) $\mathrm{D}(0) \mathrm{JF}(1): \operatorname{clim} \operatorname{adv}(\mathrm{T}+\mathrm{q})$ and E.P. SSTA

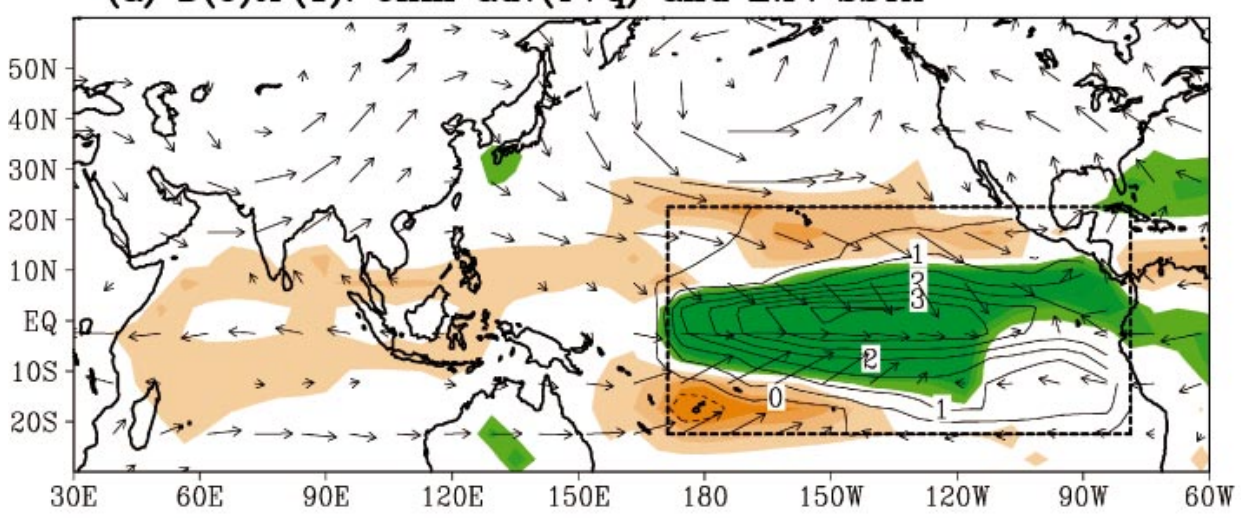

(b) $\operatorname{clim} \operatorname{adv}(\mathrm{T}+\mathrm{q})$ and all SSTA

3

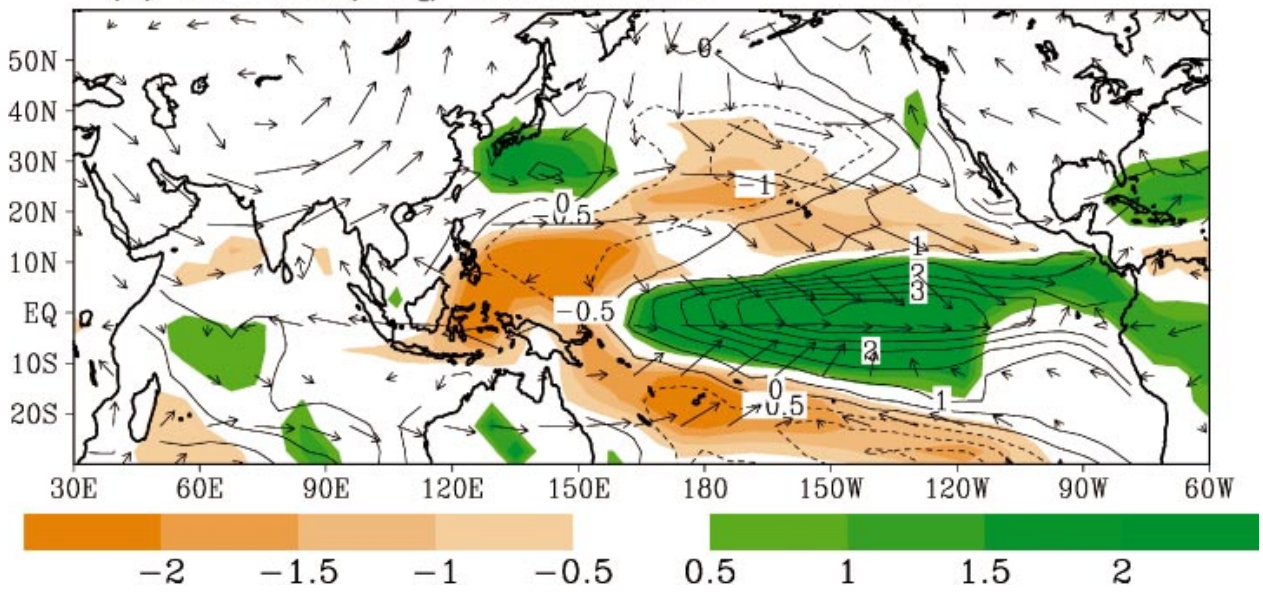

FIG. 6. As in the experiment of (a) Fig. 3b and (b) Fig. 4b but the effect of the horizontal advection of moist static energy is suppressed.

How does the negative $-\langle\mathbf{v} \cdot \nabla(T+q)\rangle^{\prime}$ form over the western North Pacific? The term, $-\langle\mathbf{v} \cdot \nabla(T+q)\rangle^{\prime}$, can be divided into $-\left\langle\overline{\mathbf{v}} \cdot \boldsymbol{\nabla}\left(T^{\prime}+q^{\prime}\right)\right\rangle$ and $-\left\langle\mathbf{v}^{\prime} \cdot \boldsymbol{\nabla}(\bar{T}\right.$ $+\bar{q})\rangle$. In the maturing winter, the tropical troposphere is warmed up by the warm SST anomalies over the eastern Pacific through wave dynamics (Su et al. 2003; Wallace et al. 1998) and $\left\langle\partial T^{\prime} / \partial y\right\rangle<0$. The vertically averaged moisture has a similar meridional gradient over the western North Pacific, so $\left\langle\partial\left(T^{\prime}+q^{\prime}\right) / \partial y\right\rangle<0$ (Fig. 7a). Since the northerly winter monsoon flow dominates the western North Pacific, $-\left\langle\overline{\mathbf{v}} \cdot \nabla\left(T^{\prime}+q^{\prime}\right)\right\rangle<0$ (Fig. 7a). Figure $7 \mathrm{~b}$ shows the distribution of $-\left\langle\mathbf{v}^{\prime} \cdot \nabla(\bar{T}+\bar{q})\right\rangle$ in the maturing winter. Strong negative $-\left\langle\mathbf{v}^{\prime} \cdot \nabla(\bar{T}+\bar{q})\right\rangle$ is found over the western North Pacific, so $-\left\langle\mathbf{v}^{\prime} \cdot \nabla(T+\right.$ $\bar{q})\rangle$ is also a factor for the negative $-\langle\mathbf{v} \cdot \nabla(T+q)\rangle^{\prime}$ over the western North Pacific. In the maturing winter, the northerly wind anomalies over the eastern part of the anomalous low-level anticyclone and strong meridional temperature and moisture gradients, that is, $\langle\partial(\bar{T}+\bar{q}) /$ $\partial y\rangle<0$, create the negative $-\left\langle\mathbf{v}^{\prime} \cdot \nabla(\bar{T}+\bar{q})\right\rangle$. Thus, both $-\left\langle\overline{\mathbf{v}} \cdot \boldsymbol{\nabla}\left(T^{\prime}+q^{\prime}\right)\right\rangle$ and $-\left\langle\mathbf{v}^{\prime} \cdot \boldsymbol{\nabla}\left(\bar{T}+\bar{q}^{\prime}\right)\right\rangle$ are negative over the western North Pacific in the maturing winter.
The similar negative $-\langle\mathbf{v} \cdot \boldsymbol{\nabla}(T+q)\rangle^{\prime}$ over the western North Pacifc is also found in experiments forced by the SST anomalies over the western Pacific and Indian Ocean. This indicates that the effect of the horizontal advection of moist static energy induces the anomalous low-level anticyclone, not only through the SST anomalies over the eastern Pacific but also through the SST anomalies over the western Pacific and Indian Ocean. Thus, in the experiment with the suppressed effect of the horizontal advection of moist static energy, the anomalous low-level anticyclone over the western North Pacific is substantially weakened, even with the SST anomalies over all oceans (Fig 6b). This cooling and drying effect of $-\langle\mathbf{v} \cdot \boldsymbol{\nabla}(T+q)\rangle^{\prime}$ is similar to a ventilation effect proposed by Chou et al. (2001).

\section{c. Other mechanisms}

1) $F^{\text {net }}$

According to (4), $F^{\text {net }}$ is determined by net solar $\left(S_{t}^{\downarrow}-S_{t}^{\uparrow}-S_{s}^{\downarrow}+S_{s}^{\uparrow}\right)$ and longwave $\left(R_{s}^{\uparrow}-R_{t}^{\uparrow}-R_{s}^{\downarrow}\right)$ 
(a) $\mathrm{D}(0) J F(1): \operatorname{vmdiv}(\mathrm{T} a+q a)$

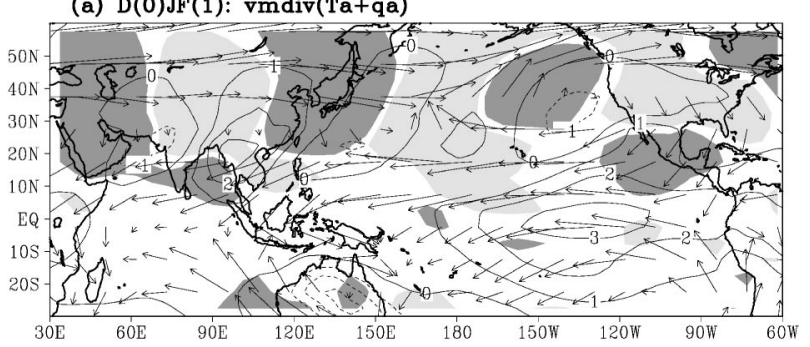

(b) $\operatorname{vadiv}(\mathrm{Tm}+\mathrm{qm})$

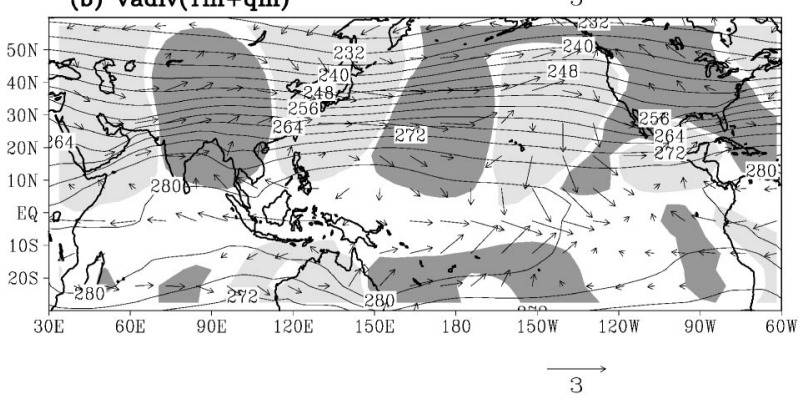

FIG. 7. (a) The $850-\mathrm{hPa} \overline{\mathbf{v}},\left\langle T^{\prime}+q^{\prime}\right\rangle$ (contour), and $-p_{T} / g\left\langle\overline{\mathbf{v}} \cdot \nabla\left(T^{\prime}\right.\right.$ $\left.\left.+q^{\prime}\right)\right\rangle$ (shading), and (b) $850-\mathrm{hPa} \mathbf{v}^{\prime},\langle\bar{T}+\bar{q}\rangle$ (contour), and $-p_{T} /$ $g\left\langle\mathbf{v}^{\prime} \cdot \nabla(\bar{T}+\bar{q})\right\rangle$ (shading) in the maturing winter obtained from the experiment of Fig. 5. Areas with values above $10 \mathrm{~W} \mathrm{~m}^{-2}$ (below -10 $\mathrm{W} \mathrm{m}^{-2}$ ) are dark (light) shaded. Both $\bar{q}$ and $q^{\prime}$ are in temperature unit (K). Divided by $L / C_{p}$ to transfer back to moisture unit $\left(\mathrm{kg} \mathrm{kg}^{-1}\right)$. The contour interval is $1 \mathrm{~K}$ for (a) and $4 \mathrm{~K}$ for (b).

radiation, sensible heat, and evaporation. Assuming small horizontal advection of moist static energy in the Tropics, that is, small gradients of temperature and moisture, $F^{\text {net }}$ should be balanced by vertical motion and divergent circulation. Positive $F^{\text {net }}$ is associated with the rising motion and low-level convergence that is accompanied by convection. A detailed discussion of the physical meaning of $F^{\text {net }}$ can be found in Chou and Neelin (2003).

Figure 5e shows positive $F^{\text {net' }}$ over the western North Pacific, and $F^{\text {net' }}$ tends to be out of phase with the $-\langle\mathbf{v} \cdot \nabla q\rangle^{\prime}$ over the western North Pacific. Since the negative $-\langle\mathbf{v} \cdot \nabla q\rangle^{\prime}$ reduces the atmospheric moisture, the corresponding evaporation is enhanced when the underlying SST is fixed. Therefore, $F^{\text {net }^{\prime}}$ is positive over the western North Pacific where $-\langle\mathbf{v} \cdot \nabla q\rangle^{\prime}$ is negative. In addition, the southward branch of the anomalous lowlevel anticyclone with mean northerly winter monsoon flow in the background also enhances evaporation over the western North Pacific. There is a strong cancellation between $F^{\text {net }}$ and $-\langle\mathbf{v} \cdot \nabla q\rangle^{\prime}$ in this experiment. If the underlying SST is allowed to vary, the positive evaporation anomalies should reduce the SST. The colder SST then suppresses evaporation and $F^{\text {net }}$, so $F^{\text {net' }}$ should be smaller than that in Fig. 5e. The observation (Fig. 1b) shows negative SST anomalies over the western Pacific, so the effect of $F^{\text {net }}$ in the experiment of Fig. 5 discussed above is substantially modified. The analysis of the experiment with the SST anomalies only over the western Pacific (Fig. 4c) indicates that negative

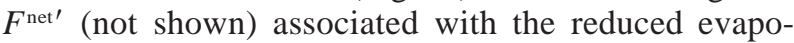
ration and surface heat fluxes is induced by the cold SST anomalies over the western Pacific. This negative $F^{\text {net }}$ then suppresses convection over the western North Pacific. Thus, the direct effect of the SST anomalies over the western Pacific on suppressing the convection over the western North Pacific is related to the effect of $F^{\text {net' }}$.

\section{2) The AnOmalous gross moist StABiLity $\left(M^{\prime}\right)$ MECHANISM}

The effect of $-M^{\prime} \boldsymbol{\nabla} \cdot \overline{\mathbf{v}}_{\mathbf{1}}$ is a convergence feedback associated with the change of the gross moist stability, so it is called the anomalous gross moist stability $\left(M^{\prime}\right)$ mechanism (Chou and Neelin 2004). The gross moist stability is balanced by two large terms: low-level moisture and maximum depth of convection (Yu et al. 1998). An increase of low-level moisture reduces $M$, while an increase of maximum depth of convection enhances $M$. An increase of low-level moisture enhances convection that is associated with the increase of maximum depth of convection, so the strong cancellation between these two effects tends to keep $M$ relatively constant in the Tropics. In the calculation, the maximum depth of convection is calculated by assuming equal moist static energy at cloud base and cloud top. However, the maximum depth of convection highly depends on the cumulus parameterization in climate models, so the $M^{\prime}$ mechanism might vary among models. In the current QTCM1, $M^{\prime}$ is mainly determined by the low-level moisture effect; $M^{\prime}$ is negative when moisture increases.

The effectiveness of the $M^{\prime}$ mechanism also depends on $\boldsymbol{\nabla} \cdot \overline{\mathbf{v}}_{\mathbf{1}}$. The El Niño warm SST anomalies over the eastern Pacific induce an anomalous ascending motion over the descending branch of the Walker circulation. This anomalous ascending motion might weaken the Walker circulation and create a subsidence anomaly over the ascending branch of the Walker circulation in the western Pacific, so the moisture over the ascending branch of the Walker circulation is reduced and $M^{\prime}$ is positive. Since $\boldsymbol{\nabla} \cdot \overline{\mathbf{v}}_{\mathbf{1}}>0$ over the ascending branch of the Walker circulation, the $M^{\prime}$ mechanism induces a cooling tendency over the ascending branch of the Walker circulation, that is, $-M^{\prime} \boldsymbol{\nabla} \cdot \overline{\mathbf{v}}_{\mathbf{1}}<0$. However, both the NCEP reanalysis and the model simulations show little change of moisture over the ascending branch of the Walker circulation (not shown). Figure 5f shows very small values of $-M^{\prime} \boldsymbol{\nabla} \cdot \overline{\mathbf{v}}_{\mathbf{1}}$ over the western North Pacific. Therefore, the $M^{\prime}$ mechanism has little influence on inducing the anomalous low-level anticyclone over the western North Pacific. The similar weak effect of the $M^{\prime}$ mechanism is also found for the experiment with the warm SST anomalies over the Indian Ocean (Fig. 4d). 


\section{d. Seasonal variation of the forcings}

Based on the discussion above, the effect of the horizontal advection of moist static energy and the $F^{\text {net' }}$ effect induced by the cold SST anomalies over the western Pacific are two major mechanisms that induce the anomalous low-level anticyclone over the western North Pacific. The effect of $-\langle\mathbf{v} \cdot \boldsymbol{\nabla}(T+q)\rangle^{\prime}$ depends on $\overline{\mathbf{v}}$ and $\boldsymbol{\nabla}(\bar{T}+\bar{q})$ over the western North Pacific, so the effect of $-\langle\mathbf{v} \cdot \nabla(T+q)\rangle^{\prime}$ tends to lock with seasonal cycle. In summer, the monsoon flow is dominated by southerly winds and $\nabla(\bar{T}+\bar{q})$ is weak over the western North Pacific, so $-\langle\mathbf{v} \cdot \nabla(T+q)\rangle^{\prime}$ tends to be positive but relatively weak. In winter, the northerly monsoon flow and strong negative $\nabla(\bar{T}+\bar{q})$ produce a strong cooling and drying effect of $-\langle\mathbf{v} \cdot \nabla(T+q)\rangle^{\prime}$. This seasonal variation of $-\langle\mathbf{v} \cdot \nabla(T+q)\rangle^{\prime}$ corresponds well with the low-level wind anomalies over the western North Pacific (Fig. 1). The effect of the cold SST anomalies over the western Pacific, however, is similar throughout the entire ENSO event because of the persistence of the cold SST anomalies. The changing sign of the low-level wind anomalies over the similar underlying SST anomalies implies different atmosphereocean coupling processes between the developing summer and the maturing winter (Chou et al. 2003). In the developing summer, the SST anomalies are a response to the atmospheric forcing (e.g., Lau et al. 2000; Wang et al. 2001). In the maturing winter, the SST anomalies are a forcing that induces the anomalous low-level anticyclone.

\section{Eastward movement of the low-level wind anomalies}

Figure 8 shows the differences of $850-\mathrm{hPa}$ winds, precipitation, and $-\langle\mathbf{v} \cdot \boldsymbol{\nabla}(T+q)\rangle$ between the El Niño and La Niña experiments with the SST anomalies over the eastern Pacific from the September of ENSO developing year (year 0) to the January of ENSO maturing year (year 1). An anomalous low-level anticyclone moves eastward from South Asia to the western North Pacific. The eastward movement of the anomalous anticyclone is similar to the observation in Fig. 2. The corresponding negative precipitation anomalies in Fig. 8 also move eastward with a jump between October and November. However, the simulated anomalous anticyclone does not extend as far northward as the observation in the ENSO mature phase. In September (year 0 ), the simulated anomalous low-level anticyclone locates more eastward, at $75^{\circ} \mathrm{E}$, than the observed anomalous anticyclone at $60^{\circ} \mathrm{E}$.

The moist static energy budget analysis (Fig. 5) shows that the effect of the horizontal advection of moist static energy is the dominant mechanism for inducing the anomalous low-level anticyclone over the western North Pacific, so the effect of $-\langle\mathbf{v} \cdot \nabla(T+$ $q)\rangle^{\prime}$ is examined and the results are shown in Fig. 8.
The negative $-\langle\mathbf{v} \cdot \nabla(T+q)\rangle^{\prime}$ moves eastward from the Bay of Bengal to the western North Pacific and reaches maximum amplitude in December. This seasonal variation of $-\langle\mathbf{v} \cdot \nabla(T+q)\rangle^{\prime}$ corresponds well with the eastward movement of the anomalous low-level anticyclone. In the experiment without the effect of the horizontal advection of moist static energy but forced by the SST anomalies over all oceans (Fig. 6b), the anomalous low-level anticyclone is over the western North Pacific without any movement (not shown). This provides evidence that the mechanism of the horizontal advection of moist static energy determines the eastward movement of the anomalous low-level anticyclone.

To understand how the term $-\langle\mathbf{v} \cdot \nabla(T+q)\rangle^{\prime}$ varies with season, $-\left\langle\overline{\mathbf{v}} \cdot \boldsymbol{\nabla}\left(T^{\prime}+q^{\prime}\right)\right\rangle$ and $-\left\langle\mathbf{v}^{\prime} \cdot \boldsymbol{\nabla}(\bar{T}+\bar{q})\right\rangle$ are examined separately. The seasonal variations of $-\left\langle\overline{\mathbf{v}} \cdot \boldsymbol{\nabla}\left(T^{\prime}+q^{\prime}\right)\right\rangle$ and $-\left\langle\mathbf{v}^{\prime} \cdot \boldsymbol{\nabla}(\bar{T}+\bar{q})\right\rangle$ are shown in Figs. 9 and 10 , respectively; $-\left\langle\overline{\mathbf{v}} \cdot \nabla\left(T^{\prime}+q^{\prime}\right)\right\rangle$ is examined first. Negative meridional gradient of $\left\langle T^{\prime}+q^{\prime}\right\rangle$ induced by ENSO exists over the western North Pacific throughout the entire ENSO event (Fig. 9). When the mean northerly winter monsoon flow starts to dominate the eastern part of Asia between September and October (Figs. 9a and 9b), the effect of $-\left\langle\overrightarrow{\mathbf{v}} \cdot \nabla\left(T^{\prime}+q^{\prime}\right)\right\rangle$ transports low moist static energy air into South Asia. This cooling tendency suppresses convection over South Asia and induces an anomalous low-level anticyclone over South Asia. This cooling tendency moves into the western North Pacific from South Asia when the winter monsoon flow reaches its maximum strength in December (year 0).

When the anomalous low-level anticyclone first appears over South Asia, the meridional gradient of mean temperature and moisture also becomes enhanced (Fig. 10a). Then the effect of $-\left\langle\mathbf{v}^{\prime} \cdot \nabla(\bar{T}+\bar{q})\right\rangle$ transports low moist static energy air into the eastern part and high moist static energy air into the western part of the anomalous low-level anticyclone (Fig. 10). This east-west pattern of the cooling-warming tendency tends to move the anomalous low-level anticyclone eastward. Since the negative $\nabla(\bar{T}+\bar{q})$ reaches its maximum value around December, the maximum cooling tendency of $-\left\langle\mathbf{v}^{\prime}\right.$. $\boldsymbol{\nabla}(\bar{T}+\bar{q})\rangle$ over the western North Pacific is also found in December (year 0). Note that the Tibetan Plateau might play a role in the early stage of the eastward movement of the anomalous low-level anticyclone by blocking the horizontal advection of moist static energy in the lower troposphere. The current QTCM1 does not include the effect of the physical topography of the Tibetan Plateau, so this might imply caveats on the effect of $-\langle\mathbf{v} \cdot \boldsymbol{\nabla}(T+q)\rangle^{\prime}$ on the eastward movement of the anomalous low-level anticyclone at the early stage.

\section{Discussion and conclusions}

Based on the analysis of the moist static energy budget, the suppressed convection that induces the anomalous low-level anticyclone over the western North Pa- 
(a) $\operatorname{SEP}(0)$ : E.P. SSTA
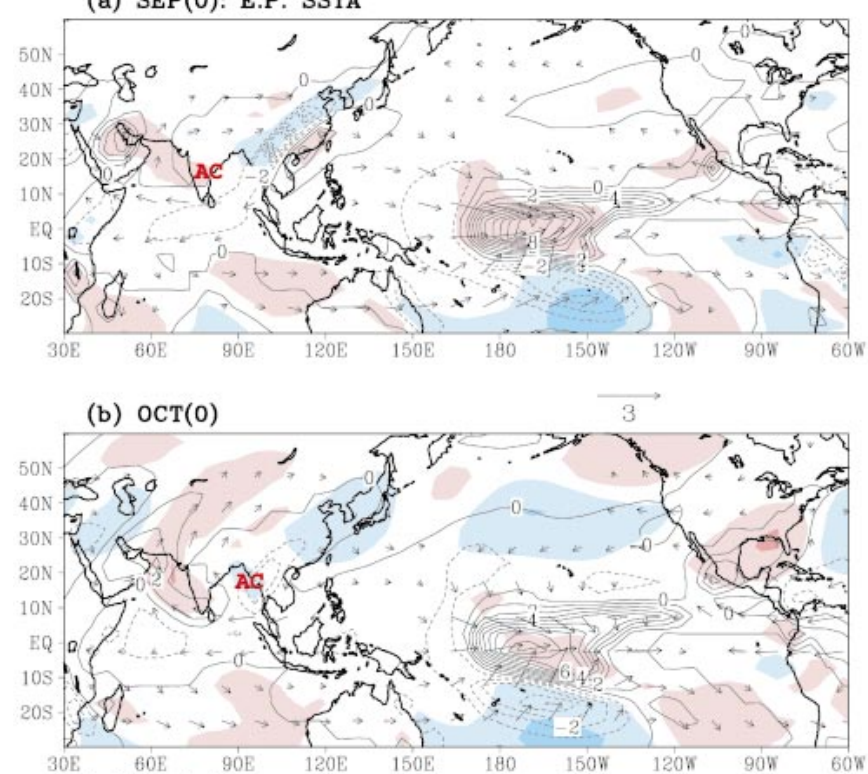

(c) $\operatorname{NOV}(0)$

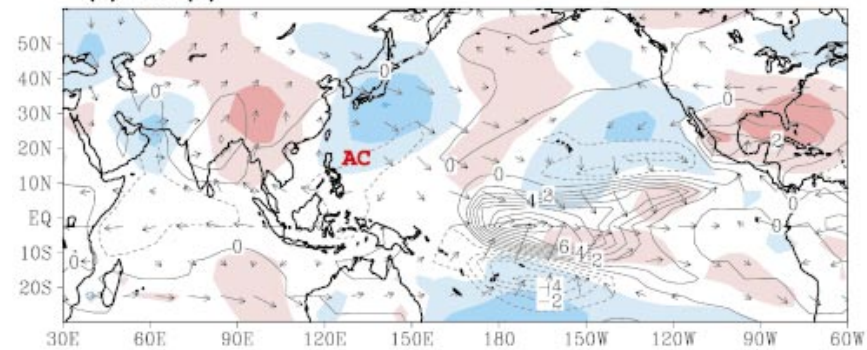

(d) $\operatorname{DEC}(0)$

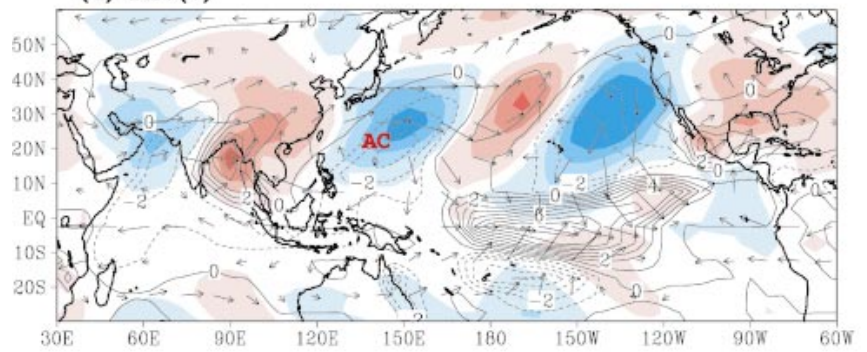

(e) JAN(1)

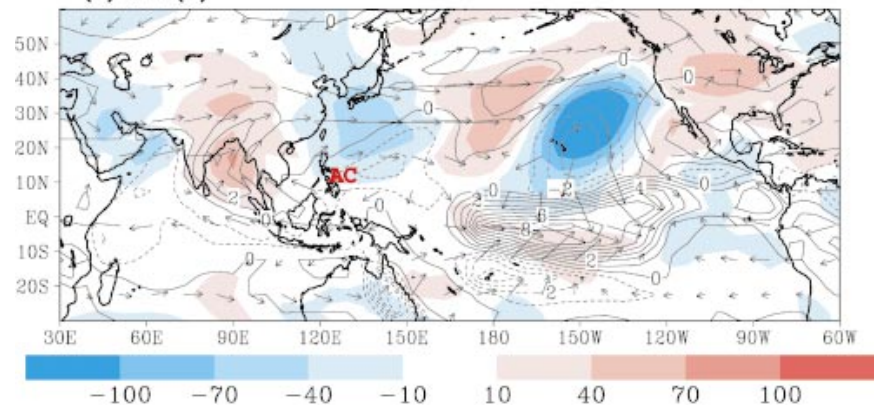

FIG. 8. Differences of 850-hPa wind anomalies, precipitation (contour), and $-p_{T} / g\langle\mathbf{v} \cdot \boldsymbol{\nabla}(T+q)\rangle^{\prime}$ (shading) obtained from the experiment of Fig. 5 for (a) $\operatorname{Sep}(0)$, (b) $\operatorname{Oct}(0)$, (c) $\operatorname{Nov}(0)$, (d) $\operatorname{Dec}(0)$, and $\operatorname{Jan}(1)$. The contour interval is $1 \mathrm{~mm} \mathrm{day}^{-1}$. 
(a) SEP(0): E.P. SSTA
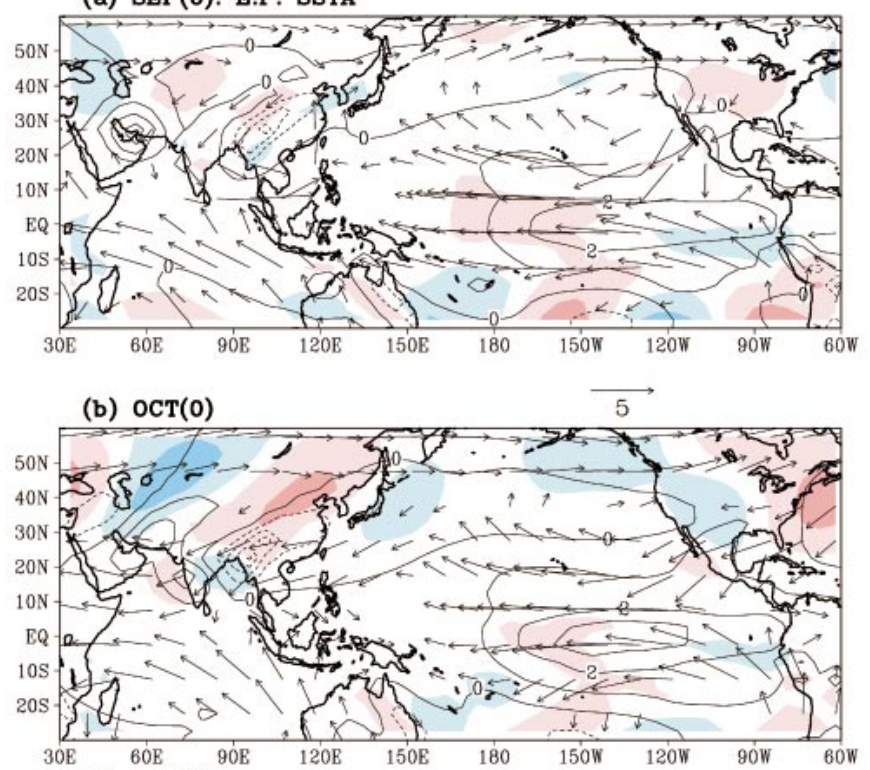

(c) $\operatorname{NOV}(0)$

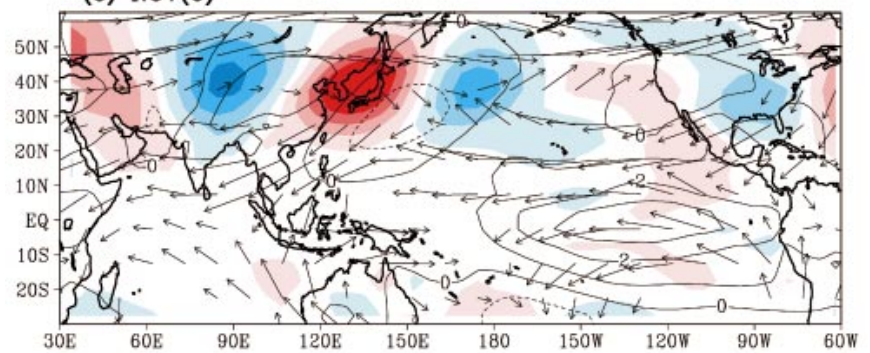

(d) $\operatorname{DEC}(0)$

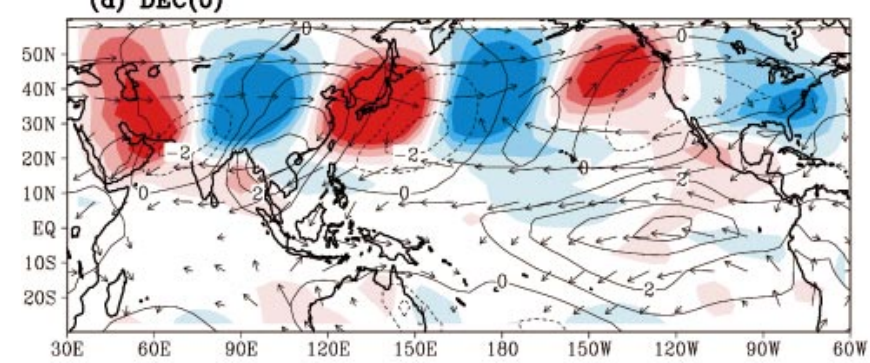

(e) JAN(1)

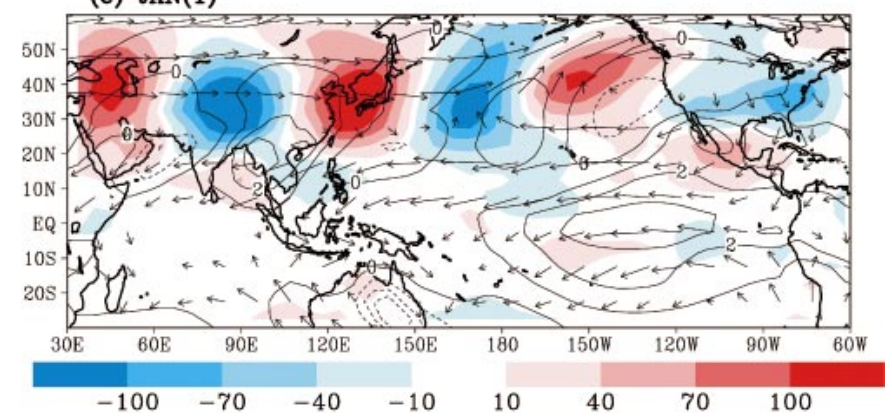

FIG. 9. As in Fig. 8 but for differences of $850-\mathrm{hPa} \overline{\mathbf{v}},\left\langle T^{\prime}+q^{\prime}\right\rangle$ (contour), and $-p_{T} / g\left\langle\overline{\mathbf{v}} \cdot \nabla\left(T^{\prime}+q^{\prime}\right)\right\rangle$ (shading). The moisture anomalies are in temperature units and the contour interval is $1 \mathrm{~K}$. 
(a) $\operatorname{SEP}(0)$ : E.P. SSTA

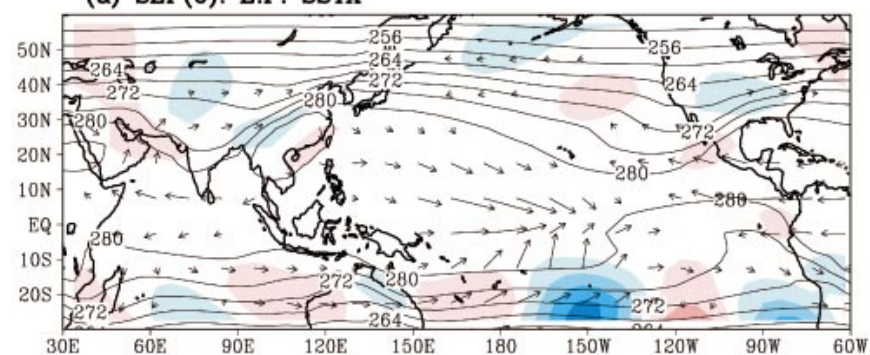

(b) $\operatorname{ocT}(0)$

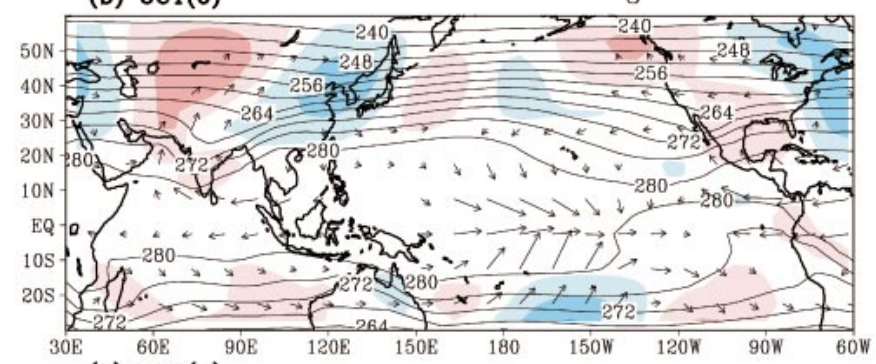

(c) $\operatorname{NOV}(0)$

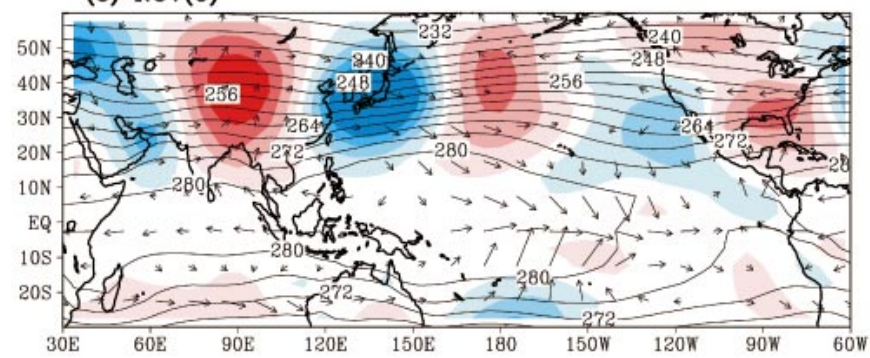

(d) $\operatorname{DEC}(0)$

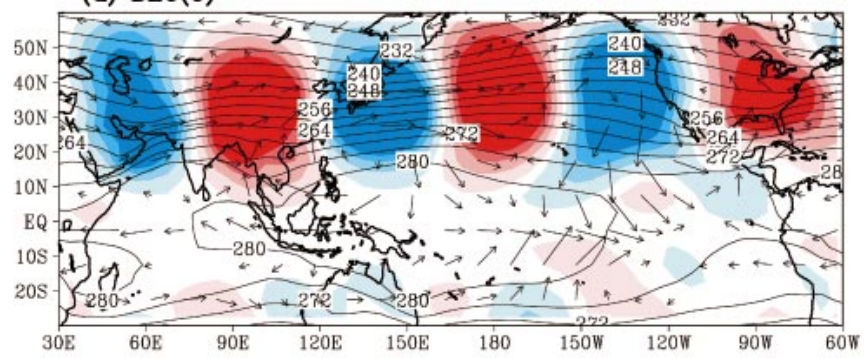

(e) $\operatorname{JAN}(1)$

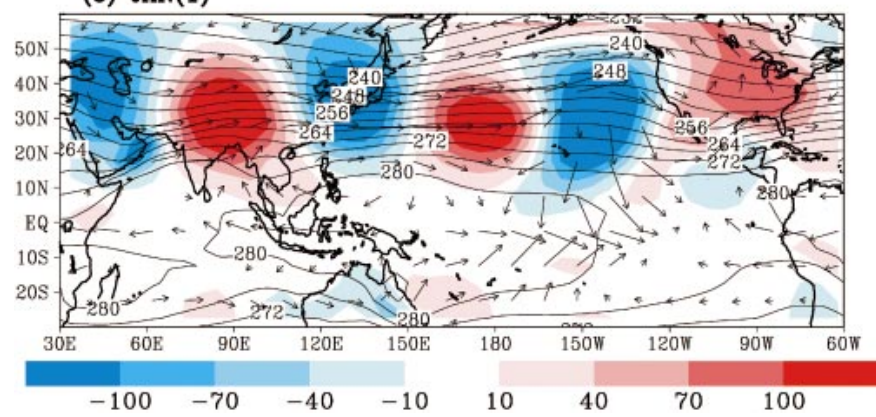

FIG. 10. As in Fig. 8 but for differences of $850-\mathrm{hPa} \mathbf{v}^{\prime},\langle\bar{T}+\bar{q}\rangle$ (contour), and $-p_{T} / g\left\langle\mathbf{v}^{\prime} \cdot \nabla(\bar{T}+\bar{q})\right\rangle$ (shading). The mean moisture is in temperature units and the contour interval is $4 \mathrm{~K}$. 

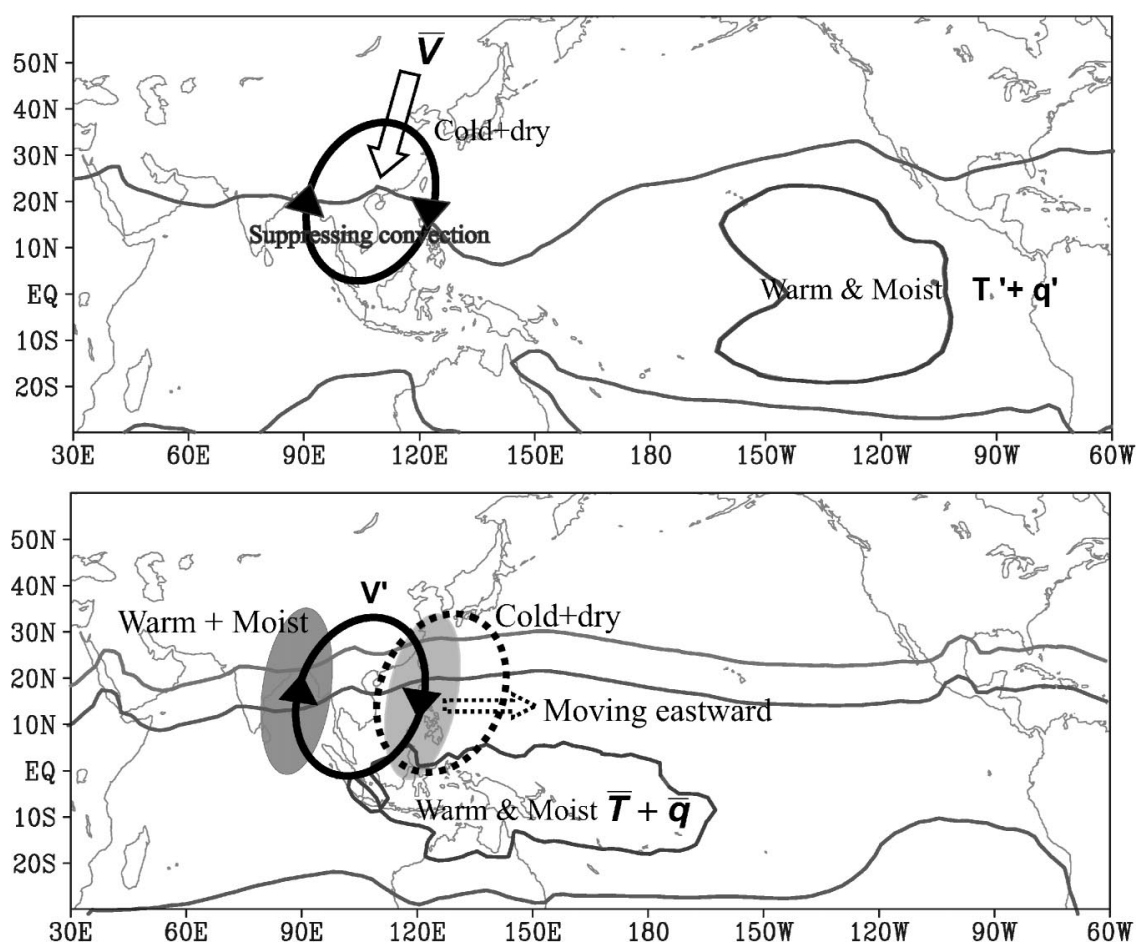

FIG. 11. Schematic diagram for the mechanism of the horizontal advection of moist static energy that induces the anomalous low-level anticyclone that moves eastward to the western North Pacific in the El Niño mature phase.

cific is mainly attributed to the cooling (drying) effect associated with the mechanism of the horizontal advection of moist static energy, $-\langle\mathbf{v} \cdot \nabla(T+q)\rangle^{\prime}$. This mechanism involves anomalies of temperature, moisture, and winds induced by ENSO and the mean state of the western North Pacific-East Asian winter climate. During an El Niño event, the anomalous winds with strong negative meridional temperature and moisture gradients of the mean state in the background and the anomalous temperature and moisture with the northerly winter monsoon flow in the background transport low moist static energy into the western North Pacific, which suppresses convection and produces the anomalous lowlevel anticyclone over the western North Pacific. Since the El Niño-related SST anomalies over the eastern Pacific, the western Pacific, and the Indian Ocean all produce a negative meridional gradient of temperature and moisture anomalies, that is, $\left\langle\partial\left(T^{\prime}+q^{\prime}\right) / \partial y\right\rangle<0$ over the western North Pacific (Fig. 7a), the effect of $-\langle\mathbf{v} \cdot \nabla(T+q)\rangle^{\prime}$ is related to all three SST anomalies with the strongest effect contributed by the warm SST anomalies over the eastern Pacific. The cold SST anomalies over the western Pacific can also suppress convection over the western North Pacific directly and produce a weak anomalous low-level anticyclone over the western North Pacific through the $F^{\text {net' }}$ effect.

The observation shows that the anomalous low-level anticyclone originates from South Asia, then moves eastward, and is established over the western North Pa- cific in the fall of the El Niño developing year. Figure 11 is a schematic diagram for the main mechanism that induces the eastward movement of the anomalous lowlevel anticyclone. During an El Niño event, the warm SST anomalies over the eastern Pacific warm up the entire tropical troposphere through wave propagation, and the tropospheric temperature anomalies, $\left\langle T^{\prime}\right\rangle$, decrease with latitudes. The meridional gradient of the associated moisture anomalies over the western North Pacific is also negative. When the winter monsoon starts to dominate Asia in fall, the northerly component of the winds transports low moist static energy air into the south, that is, $-\left\langle\overline{\mathbf{v}} \cdot \nabla\left(T^{\prime}+q^{\prime}\right)\right\rangle<0$, so convection over South Asia is suppressed. The suppressed convection then induces an anomalous low-level anticyclone in South Asia (Fig. 11a). The northerly component of the winter monsoon reaches its maximum strength in winter, so the anomalous low-level anticyclone is intensified in the El Niño maturing winter. Meanwhile, the mean state of the troposphere is warm and moist in the Tropics and cold and dry at higher latitudes, so the values of $\partial(\bar{T}+\bar{q}) \partial y$ is negative. The meridional components of the anomalous low-level anticyclone then transport cold and dry air from the north to the eastern part of the anomalous low-level anticyclone and warm and moist air from south to the western part of the anomalous low-level anticyclone. The negative $\partial(\bar{T}+$ $\bar{q}) \partial y$ over the western North Pacific is significantly enhanced in winter, so the cooling-warming pattern of 
$-\left\langle\mathbf{v}^{\prime} \cdot \nabla(\bar{T}+\bar{q})\right\rangle$ is also intensified. This east-west pattern of the cooling-warming tendency associated with $-\left\langle\mathbf{v}^{\prime} \cdot \nabla(\bar{T}+\bar{q})\right\rangle$ tends to move the suppressed convection and the anomalous low-level anticyclone eastward (Fig. 11b) in the El Niño developing year. This mechanism implies that the anomalous low-level anticyclone is seasonally locked with the mean state of the western North Pacific-East Asian climate.

This study proposes a different view on how the El Niño SST anomalies contribute to the establishment of the anomalous low-level anticyclone, which also involves the western North Pacific-East Asian winter climate. With the western North Pacific-East Asian mean state in the background, the El Niño-induced anomalies over the western North Pacific create a favorable condition for the mechanism of the horizontal advection of moist static energy. This model does not include topography, leading to some caveats related to the physical existence of the Tibetan Plateau. A further examination should be carried out with more comprehensive models, such as GCMs.

Acknowledgments. This work was supported under National Science Council Grant 91-2111-M-001-002 and the Environmental Change Research Project of Academia Sinica. Special thanks to Professor C.-H. Sui for his valuable comments. The author also thank Drs. C.-P. Chang, H.-H. Hsu, LinHo, M.-M. Lu, J. D. Neelin, and J.-Y. Yu for discussions, and Dr. Jien-Yi Tu and Ms. Zen-Yi Liu for graphics. The comments and suggestions from Drs. M. P. Hoerling and H. Su and an anonymous reviewer were very useful in improving this paper.

\section{REFERENCES}

Betts, A. K., and M. J. Miller, 1993: The Betts-Miller scheme. The Representation of Cumulus Convection in Numerical Models of the Atmosphere, Meteor. Monogr., No. 46, Amer. Meteor. Soc., 107-121.

Chang, C.-P., Y. Zhang, and T. Li, 2000a: Interannual and interdecadal variations of the East Asian summer monsoon and tropical Pacific SSTs. Part I: Roles of the subtropical ridge. J. Climate, 13, $4310-4325$.

$\ldots, \ldots$, and $-2000 \mathrm{~b}$ : Interannual and interdecadal variations of the East Asian summer monsoon and tropical Pacific SSTs. Part II: Meridional structure of the monsoon. J. Climate, 13, 4326-4340.

Chen, L., M. Dong, and Y. Shao, 1992: The characteristics of interannual variations on the East Asian monsoon. J. Meteor. Soc. Japan, 70, 397-421.

Chou, C., and J. D. Neelin, 1996: Linearization of a longwave radiation scheme for intermediate tropical atmospheric models. $J$. Geophys. Res., 101, 15 129-15 145.

—, and ——, 1999: Cirrus detrainment-temperature feedback. Geophys. Res. Lett., 26, 1295-1298.

— the northern summer monsoons over North America, Asia, and Africa. J. Climate, 16, 406-425.

- , and,- 2004 : Mechanisms of global warming impacts on regional tropical precipitation. J. Climate, in press.

,$- \ldots$, and H. Su, 2001: Ocean-atmosphere-land feedbacks in an idealized monsoon. Quart. J. Roy. Meteor. Soc., 127, 18691891.

_, J.-T. Tu, and J.-Y. Yu, 2003: Interannual variability of the western North Pacific summer monsoon: Differences between ENSO and non-ENSO years. J. Climate, 16, 2275-2287.

Fu, Q., and K. N. Liou, 1993: Parameterization of the radiative properties of cirrus clouds. J. Atmos. Sci., 50, 2008-2025.

Harshvardhan, R. Davies, D. A. Randall, and T. G. Corsetti, 1987: A fast radiation parameterization for general circulation models. J. Geophys. Res., 92, 1009-1016.

Huang, R., and F. Sun, 1992: Impacts of the tropical western Pacific on the East Asian summer monsoon. J. Meteor. Soc. Japan, 70, 243-256.

Kalnay, E., and Coauthors, 1996: The NCEP/NCAR 40-Year Reanalysis Project. Bull. Amer. Meteor. Soc., 77, 437-471.

Kawamura, R., T. Matsuura, and S. Iisuka, 2001: Interannual atmosphere-ocean variations in the tropical western North Pacific relevant to the Asian summer monsoon-ENSO coupling. J. Meteor. Soc. Japan, 79, 883-898.

Larkin, N. K., and D. E. Harrison, 2002: ENSO warm (El Niño) and cold (La Niña) event life cycles: Ocean surface anomaly patterns, their symmetries, asymmetries, and implications. J. Climate, 15, 1118-1140.

Lau, K.-M., and W. Bua, 1998: Mechanism of monsoon-Southern Oscillation coupling: Insights from GCM experiments. Climate Dyn., 14, 759-779.

_ , and H. T. Wu, 2001: Principal modes of rainfall-SST variability of the Asian summer monsoon: A reassessment of the monsoonENSO relationship. J. Climate, 14, 2880-2895.

_, K.-M. Kim, and S. Yang, 2000: Dynamical and boundary forcing characteristics of regional components of the Asian summer monsoon. J. Climate, 13, 2461-2482.

Lau, N.-C., and M. J. Nath, 2000: Impact of ENSO on the variability of the Asian-Australian monsoons as simulated in GCM experiments. J. Climate, 13, 4287-4309.

$\ldots$, and - 2003: Atmosphere-ocean variations in the IndoPacific sector during ENSO episodes. J. Climate, 16, 3-20.

Neelin, J. D., and J.-Y. Yu, 1994: Modes of tropical variability under convective adjustment and the Madden-Julian Oscillation. Part I: Analytical theory. J. Atmos. Sci., 51, 1876-1894.

—_, and N. Zeng, 2000: A quasi-equilibrium tropical circulation model-Formulation. J. Atmos. Sci., 57, 1741-1766.

Nitta, T., 1987: Convective activities in the tropical western Pacific and their impacts on the Northern Hemisphere summer circulation. J. Meteor. Soc. Japan, 65, 165-171.

Rasmusson, E. M., and T. H. Carpenter, 1982: Variations in tropical sea surface temperature and surface wind fields associated with the Southern Oscillation/El Niño. Mon. Wea. Rev., 110, 354384.

Smith, T. M., R. W. Renolds, R. E. Livezey, and D. C. Stokes, 1996: Reconstruction of historical sea surface temperatures using empirical orthogonal functions. J. Climate, 9, 1403-1420.

Su, H., and J. D. Neelin, 2002: Teleconnection mechanisms for tropical Pacific descent anomalies during El Niño. J. Atmos. Sci., 59, 2694-2712.

—,- , and J. E. Meyerson, 2003: Sensitivity of tropical tropospheric temperature to sea surface temperature forcing. J. Climate, 16, 1283-1301.

Tanaka, M., 1997: Interannual and interdecadal variations of the western North Pacific monsoon and the East Asian Baiu rainfall and their relationship to ENSO cycles. J. Meteor. Soc. Japan, 75, 1109-1123.

Wallace, J. M., T. P. Mitchell, E. M. Rasmusson, V. E. Kousky, E. S. Sarachik, and H. von Storch, 1998: On the structure and evolution of ENSO-related climate variability in the tropical Pacific: Lessons from TOGA. J. Geophys. Res., 103, $14241-$ 14260 .

Wang, B., and Q. Zhang, 2002: Pacific-East Asian teleconnection. Part II: How the Philippine Sea anomalous anticyclone is es- 
tablished during El Niño development. J. Climate, 15, 32523265 .

- R. Wu, and X. Fu, 2000: Pacific-East Asian teleconnection: How does ENSO affect East Asian climate? J. Climate, 13, $1517-1536$.

__ _ _ - and K.-M. Lau, 2001: Interannual variability of the Asian summer monsoon: Contrasts between the Indian and the western North Pacific-East Asian monsoons. J. Climate, 14, 4073-4090. -, - and T. Li, 2003: Atmosphere-warm ocean interaction and its impacts on Asian-Australian monsoon variation. J. Climate, 16, 1195-1211.

Watanabe, M., and F.-F. Jin, 2002: Role of Indian Ocean warming in the development of Philippine Sea anticyclone during ENSO Geophys. Res. Lett., 29, 1478, doi:10.1029/2001GL014318.

Weng, H., K.-M. Lau, and K.-K. Xue, 1999: Multi-scale summer rainfall variability over China and its long-term link to global sea surface temperature variability. J. Meteor. Soc. Japan, 77, 845-857.

Wu, R., and B. Wang, 2000: Interannual variability of summer monsoon onset over the western North Pacific and the underlying processes. J. Climate, 13, 2483-2501.

Xie, P., and P. A. Arkin, 1997: Global precipitation: A 17-year monthly analysis based on gauge observations, satellite estimates, and numerical outputs. Bull. Amer. Meteor. Soc., 78, 2539-2558.

Yu, J.-Y., and J. D. Neelin, 1994: Modes of tropical variability under convective adjustment and the Madden-Julian oscillation. Part II: Numerical results. J. Atmos. Sci., 51, 1895-1914.

C. Chou, and J. D. Neelin, 1998: Estimating the gross moist stability of the tropical atmosphere. J. Atmos. Sci., 55, 13541372.

Zeng, N., J. D. Neelin, and C. Chou, 2000: A quasi-equilibrium tropical circulation model-implementation and simulation. $J$. Atmos. Sci., 57, 1767-1796. 